\title{
SYSTEM THERMAL-HYDRAULIC MODELLING OF THE PHÉNIX DISSYMMETRIC TEST BENCHMARK
}

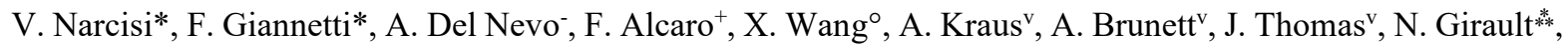 \\ B. Grosjean ${ }^{\mathrm{x}}$, G. Caruso*, A. Gerschenfeld ${ }^{\mathrm{x}}$ \\ * "Sapienza" University of Rome, DIAEE - Nuclear Section, Rome, Italy \\ -Italian National Agency for New Technologies, Energy and Sustainable Economic Development, C.R. ENEA \\ Brasimone, Italy \\ ${ }^{+}$Nuclear Research and Consultancy Group (NRG), Petten, The Netherlands \\ ${ }^{\circ}$ Karlsruhe Institute of Technology (KIT), Karlsruhe, Germany \\ v Argonne National Laboratory (ANL), Argonne, USA \\ ** Institut de Radioprotection et de Sûreté Nucléaire (IRSN), St Paul-lez-Durance, France \\ ${ }^{x}$ French Alternative Energies and Atomic Energy Commission (CEA) \\ DEN/DM2S/STMF - Service de Thermohydraulique et de Mécanique des Fluides \\ Université Paris-Saclay, F-91191, Gif-sur-Yvette, France
}

\begin{abstract}
Phénix is a French pool-type sodium-cooled prototype reactor; before the definitive shutdown, occurred in 2009, a final set of experimental tests are carried out in order to increase the knowledge on the operation and the safety aspect of the pool-type liquid metal-cooled reactors. One of the experiments was the Dissymmetric End-of-Life Test which was selected for the validation benchmark activity in the frame of SESAME project.

The computer code validation plays a key role in the safety assessment of the innovative nuclear reactors and the Phénix dissymmetric test provides useful experimental data to verify the computer codes capability in the asymmetric thermal-hydraulic behaviour into a pool-type liquid metal-cooled reactor. This paper shows the comparison of the outcomes obtained with six different System Thermal-Hydraulic (STH) codes: RELAP5-3D ${ }^{\odot}$, SPECTRA, ATHLET, SAS4A/SASSYS-1, ASTEC-Na and CATHARE. The nodalization scheme of the reactor was individually achieved by the participants; during the development of the thermal-hydraulic model, the pool nodalization methodology had a special attention in order to investigate the capability of the STH codes to reproduce the dissymmetric effects which occur in each loop and into pools, caused by the azimuthal asymmetry of the boundary conditions.

The modelling methodology of the participants is discussed and the main results are compared in this paper to obtain useful guide lines for the future modelling of innovative liquid metal pool-type reactors.
\end{abstract}

\section{INTRODUCTION}

Verification and validation of computational codes are key points for the development of the Generation IV (Gen-IV) reactors. System Thermal-Hydraulic (STH) codes spread to perform system-scale safety analysis of the Light Water-cooled Reactor (LWR) and they were validated using a large amount of experimental data. The proposal of Gen-IV reactors led to the implementation of advanced capabilities to the STH codes, which include the possibility to reproduce the thermal-hydraulics in large plena and the opportunity to adopt new coolant, such as liquid metal or molten salt.

In this framework, a validation benchmark was proposed on Horizon 2020 (H2020) SESAME project; the activity aims at comparing the capability of six STH codes to reproduce the thermal-hydraulics of a Sodium-cooled Fast Reactor (SFR) in both nominal conditions and accidental scenario. One of the scopes of this activity is the evaluations of the different source of uncertainty for the transient analysis. The Dissymmetric Test, carried out on Phénix reactor, was selected for the analysis. The experimental test, characterized by asymmetrical boundary conditions, is considered very interesting for the evaluation of the STH codes capability to reproduce relevant three-dimensional phenomena in a liquid metal pool-type reactor. The boundary conditions lead to a dissymmetrical distribution of the temperature inside the cold pool which is strongly related to the thermal-hydraulics of the primary flow path. Another benchmark was also organized for the CFD-STH coupled simulations using the same experimental data (Uitslag-Doolaard et al., in this issue).

The French Alternative Energies and Atomic Energy Commission (CEA) provided to the participants a detailed description of the reactor geometry, the system boundary conditions and the temperature evolution for the primary system over the whole transient. Seven organizations have participated to the validation benchmark: CEA, with CATHARE code, "Sapienza" University of Rome (UNIROMA1) in collaboration with the Italian National Agency for the New Technologies, Energy and Sustainable Economic Development (ENEA), with RELAP5-3D ${ }^{\odot}$ code, Nuclear Research and consultancy Group (NRG), with SPECTRA code, Argonne National Laboratory (ARGONNE), with SAS4A/SASSYS-1 code, Karlsruhe Institute of Technology (KIT), with ATHLET code, and the Institut de Radioprotection et de Sûreté Nucléaire (IRSN), with ASTEC-Na code.

The thermal-hydraulic models are presented in the following sections and the computational results are compared with the experimental data in order to assess models and correlations capabilities. 


\section{PHÉNIX REACTOR}

\section{Description of the reactor}

Phénix is a sodium-cooled pool-type fast reactor of $563 \mathrm{MW}_{\text {th }}$ nominal power $\left(250 \mathrm{MW}_{\mathrm{e}}\right)$ which operated from 1973 to 2009 at the Marcoule nuclear site (France). Figure 1 shows the reactor block, individuating the main components. The containment of the radioactive elements is ensured by three vessels: the main vessel, $11.8 \mathrm{~m}$ in diameter, contains about 800 tons of primary sodium and the whole primary system, the double-envelope vessel contains any possible sodium leaks and the primary containment vessel guarantees the containment of radioactive elements, in the event of severe accident. The final emergency cooling system is welded onto the outside wall of the third vessel; it aims at removing the decay heat in the event of a loss of normal cooling system, assuring to maintain the reactor pit concrete at ambient temperature. Inside and welded to the main vessel, a conical shell (primary vessel in Figure 1) achieves the separation between cold and hot pool and it ensures the support of the core, the strongback and the diagrid (Vasile et al., 2010).

During the normal operation of the reactor, the strongback redirect $10 \%$ of the primary flow rate from the diagrid to the Vessel Cooling System (VCS). The rest of the primary sodium flows through the reactor core. It consists of an array of hexagonal assemblies characterized by an overall length of $4.3 \mathrm{~m}$. The fuel is mixed uranium-plutonium oxide and two regions of different enrichment compose the central fissile zone of the core. The reactor core is completed with the annular fertile zone, steel reflectors, lateral shielding rods, six control rods and one safety rod (Vasile et al., 2010).

The heat generated by the core is removed by six intermediate heat exchangers (IHX), connected in pairs with three sodium secondary loops. They are straight-tube heat exchangers, connected at the inlet with the hot pool and at the outlet with the cold pool. The primary sodium moves downward shell-side, reducing its temperature. From 1993, the reactor was operated at a reduced power of $350 \mathrm{MW}_{\text {th }}$ and only four IHXs were operated, closing the inlet of two IHXs (called DOTE in Figure 2). The sodium collected inside the cold pool is driven to the diagrid by three vertical-axis primary pumps (PP); all three pumps continued to be operated after the power reduction (Vasile et al., 2010). The power produced in the core zones are reported in Table 1.

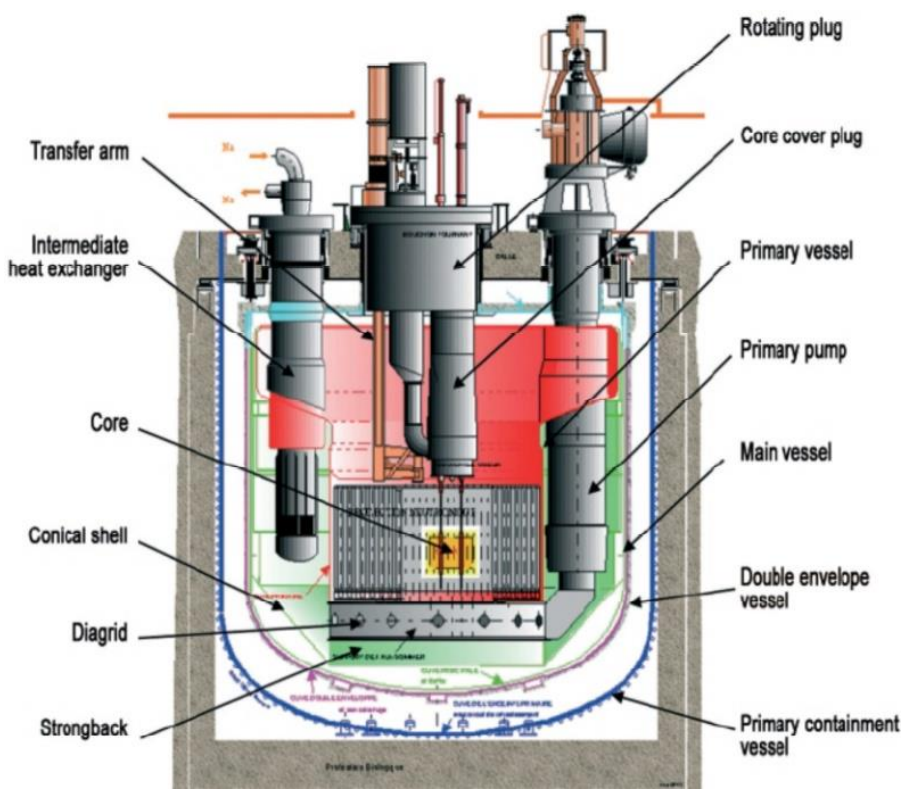

Figure 1 Phénix reactor block scheme

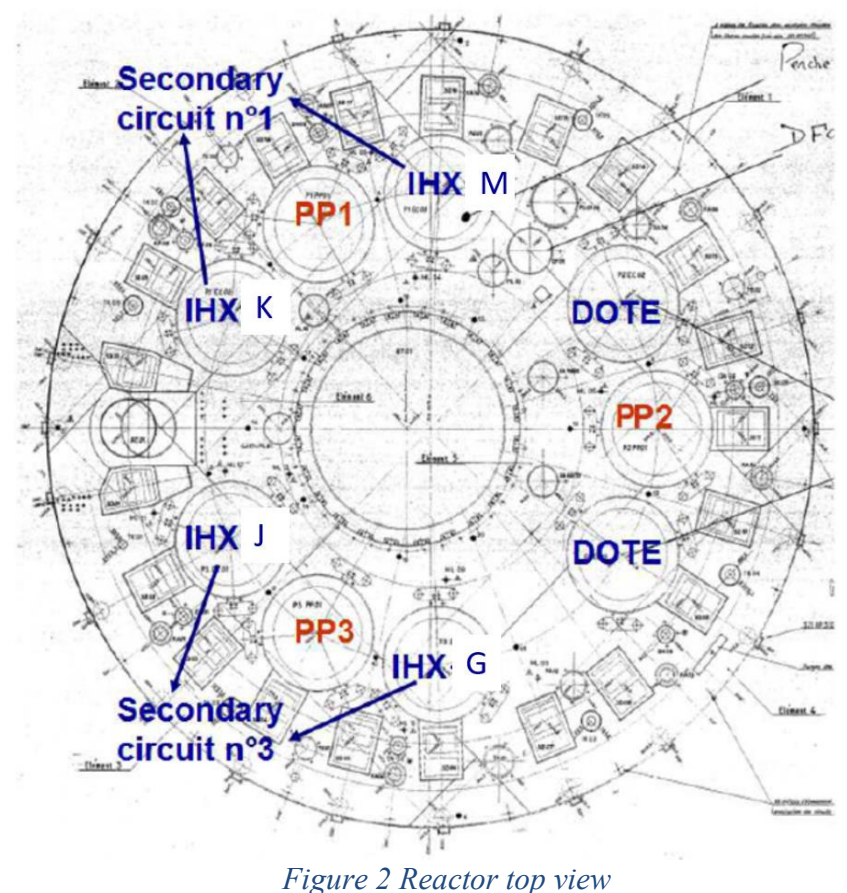

Figure 2 Reactor top view

Table 1 Configuration of the core

\begin{tabular}{llll}
\hline Core zones & Number of SA & Number of rods & Power per rod [W] \\
\hline Inner core SA & 54 & 11718 & 15437.79 \\
Outer core SA & 56 & 12152 & 11775.84 \\
Blanket zone & 86 & 5246 & 4593.98 \\
control rods and safe rod & 7 & 1519 & 537.63 \\
In containment fuel storage SA & 3 & 1302 & 1305.68 \\
Steel zone & 6 & 1272 & 3278.7 \\
\hline
\end{tabular}




\section{The dissymmetric test}

In 2009, two asymmetrical tests were performed on the secondary loops, resulting in a similar operation of the reactor. This similarity proves the repeatability of the test and the dissymmetric test on the secondary loop 1 (LOOP 1) has been selected as the transient test for the validation benchmark.

The test starts in nominal steady state conditions, with the reduced thermal power. The initiating event is the trip of the LOOP 1 secondary pump, reducing the speed from 700 to $100 \mathrm{rpm}$ in $13 \mathrm{~s}$. After $5 \mathrm{~s}$ from the beginning of the test, the automatic shutdown occurs, by the insertion of the control rods in $45 \mathrm{~s}$, and the speed of the LOOP 3 secondary pump is reduced from 700 to $110 \mathrm{rpm}$ in $60 \mathrm{~s}$. Finally, at $48 \mathrm{~s}$, the scram command is operated and the test terminated after $1800 \mathrm{~s}$ from the beginning. A broad description of the test is reported in (Uitslag-Doolaard et al., in this issue). The operating parameters are provided by CEA to the participant; the measurement uncertainties are included in the data sheet, as following:

- $\quad+/-5 \mathrm{MW}_{\text {th }}$ on the thermal power before the scram;

- $10 \%$ for the decay heat power;

- $\quad+/-5 \mathrm{~K}$ on the temperatures;

- $\quad+/-5 \%$ on the flow rates

\section{SYSTEM THERMAL-HYDRAULIC MODELLING}

\section{CEA model with CATHARE}

The CATHARE model of the Phénix reactor includes the entire primary sodium circuit but only the intermediate heat exchangers with their inlet and outlet pipes for the secondary sodium system. This is justified by the large uncertainty associated with the heat losses along the secondary loops, and because the secondary circuit behaviour is not the main purpose of this benchmark. The main reactor vessel components are the core, the hot and cold pools, the primary pumps, the reactor vessel lower plenum, the strong arm, the upper-core structure, the diagrid and the shell side of the IHXs. The transient IHX secondary inlet flowrates and temperatures measured during the dissymmetric test are used as boundary conditions for the secondary sodium system.

The core flowrate is provided by mechanical pumps defined on $1 \mathrm{D}$ elements. The diagrid is modelled with a 0D element. The core is modelled with four 1D channels ( 2 channels for the fissile sub-assemblies, 1 channel for the breeder sub-assemblies and 1 channel for the by-pass). The neutronic sub-module of the CATHARE code is not used in this calculation: the core power is imposed as a law (function of the time), in order to avoid discrepancies on this evolution and to focus on the thermal hydraulic behaviour of the primary circuit. The sub-assemblies inlet singular pressure drop coefficients are calculated and imposed to obtain the core flowrate distribution at the nominal operating conditions. The Rehme correlation is used to model the single-phase wall friction in the pins bundle. On the primary circuit side, a $1 \mathrm{D}$ element models the $\mathrm{Na} / \mathrm{Na}$ heat exchanger. The Borishanski correlation is used on the primary side of the heat exchanger to modify the exchange laws.

The pools are modelled with several 0D elements in order to capture thermal stratification (11 elements for the cold pool, 4 for the hot pool). The reactor cooling vessel is also modelled, with two 1D elements and one 0D element. Heat exchanges between these elements and these heats losses are calculated and imposed every time step. The reactor vessel cooling system is modelled by two $1 \mathrm{D}$ for the pipes and a $0 \mathrm{D}$.

The Figure 3 shows a scheme of the CATHARE model of the Phénix primary circuit.

Only the heat exchangers have been modelled on the secondary circuit. These components are composed of the following elements:

- A downward pipe which supplies the components in cold sodium, modelled by a 1D;

- A bottom vessel, modelled by a 0D;

- An upward tube bundle, where the heat exchanges with the primary circuit take place, modelled by a 1D;

- An upper vessel, modelled by a 0D.

A boundary condition imposes the temperature and the flowrate at the inlet of the components, while the outlet pressure is imposed at the outlet by another boundary condition. The exchangers' fouling factors are controlled to obtain the observed temperature at the core inlet $(655 \mathrm{~K})$ during the initial steady state.

The Figure 4 shows an overview of the CATHARE model of the Phénix primary circuits. 


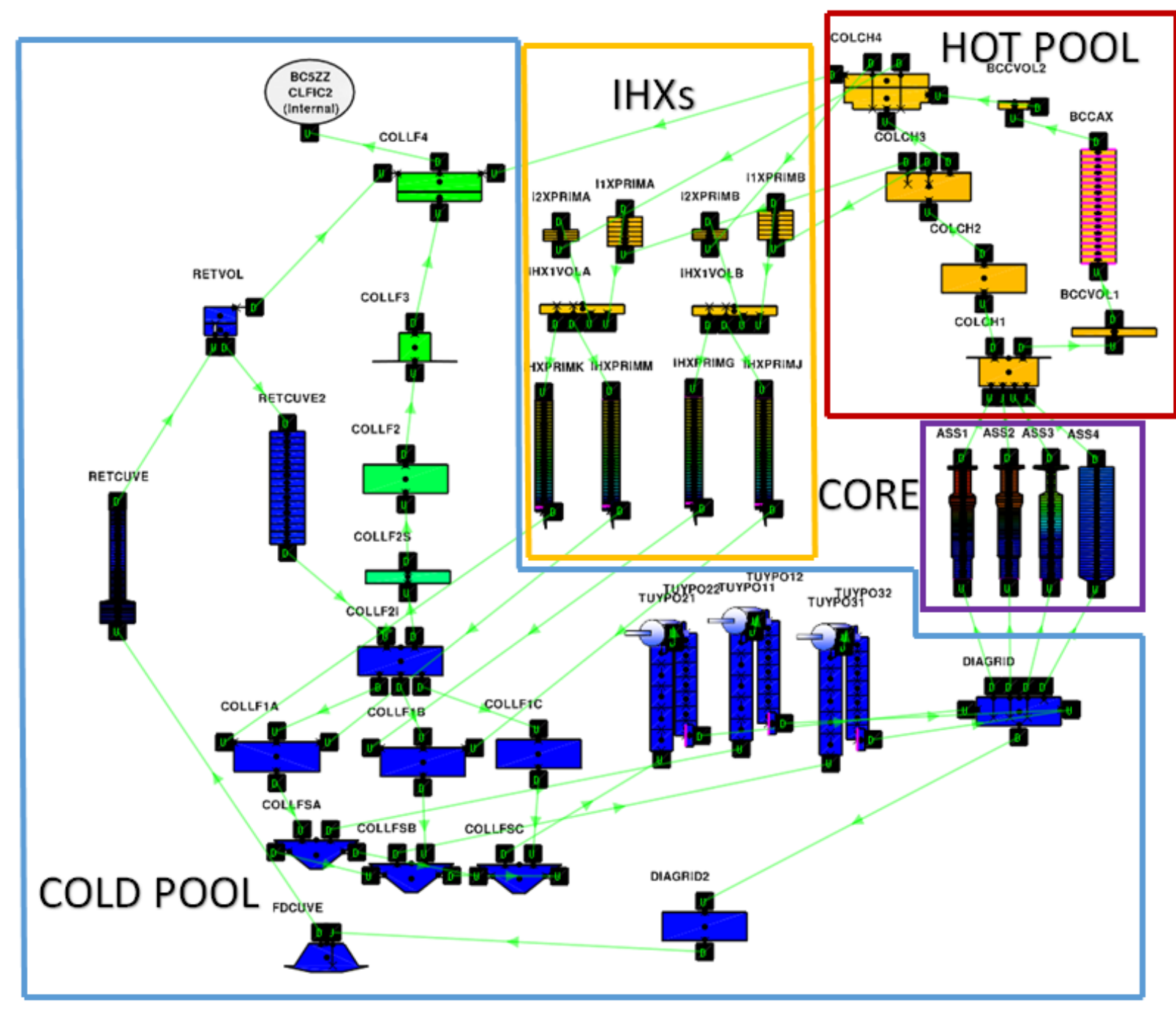

Figure 3 Overview of the CATHARE model of the Phénix primary circuit 

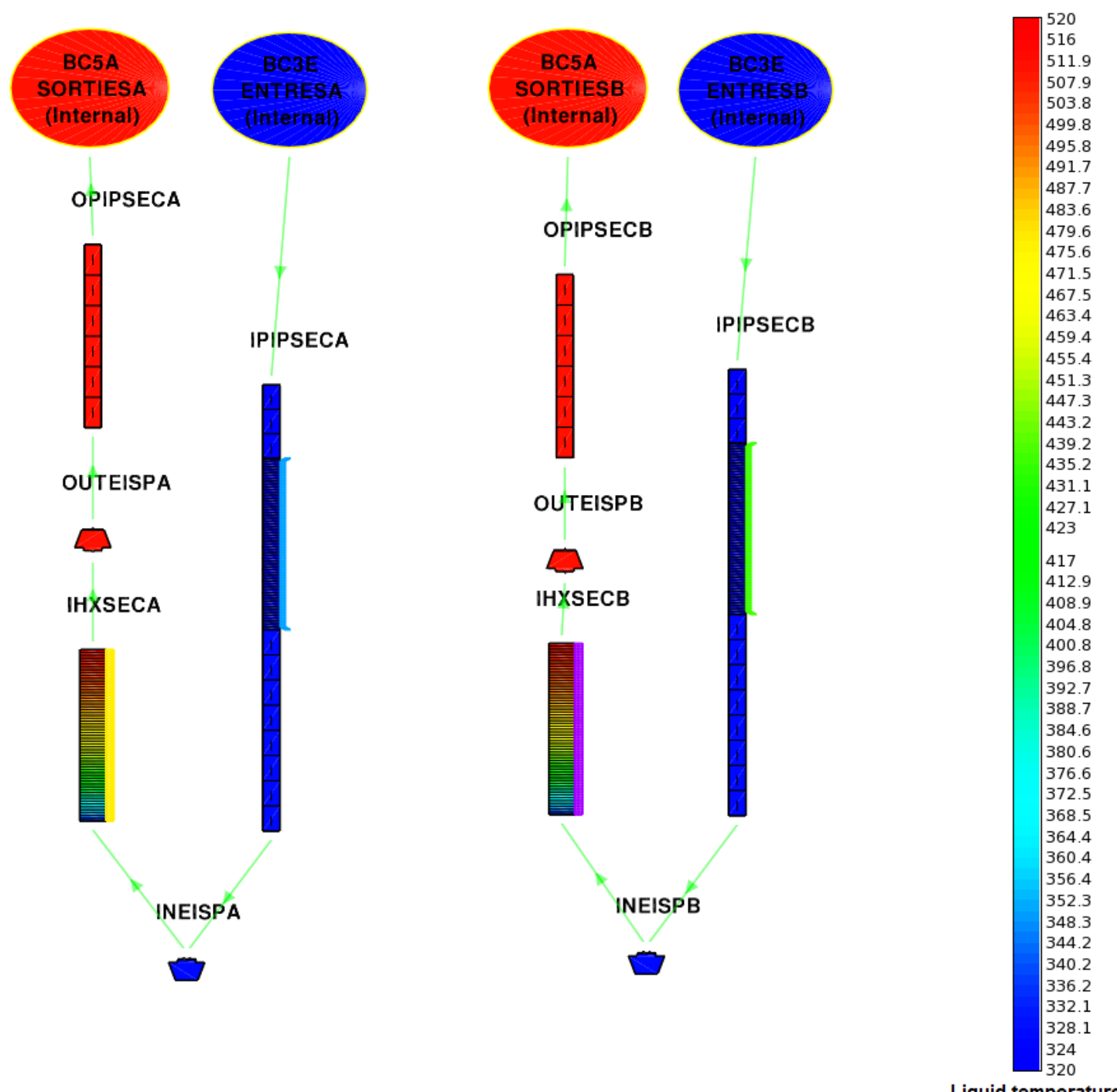

Figure 4 Overview of the CATHARE model of the Phénix secondary circuits

Liquid temperature

\section{UNIROMA1 model with RELAP5-3D ${ }^{\odot}$}

RELAP5-3D has been developed at Idaho National Laboratory. It is characterized by a fully integrated, multi-dimensional thermal hydraulic and kinetic capability, allowing the applicability to the full range of postulated reactor accidents. In order to extend the application to the liquid metal-cooled fast reactors, new working fluids are implemented in RELAP5-3D, such as sodium, lead, lead bismuth eutectic alloy and lithium-lead alloy (The RELAP5-3D ${ }^{\odot}$ Code Development Team, 2015a).

Phénix model has been developed with RELAP5-3D ver. 4.3.4; it consists of two macro regions: a mono-dimensional and a three-dimensional modelling scheme, using the same approach described in Narcisi et al., 2019b. The mono-dimensional model reproduces the main components of the primary system, except for the pools, the diagrid and the core bypass.

The reactor core is divided into three regions (Giannetti et al., 2018):

- The inner and the outer core (the first 7 rows): reproduced assembly per assembly with 127 parallel pipes;

- The blanket zone (rows greater than 7): modelled with 36 equivalent pipes, reproducing the radial blanket, the axial reflector and the storage assemblies;

- The shielding zone: simulated with 24 equivalent pipes, including axial shield and boron carbide elements.

The modelling scheme of the IHXs is presented in Figure 5, showing a pair of heat exchangers. They are modelled separately with six mono-dimensional pipe components, connected in the correspondent region of the hot and cold pool, following the schematic view shown in Figure 6. The IHXs secondary side are also simulated separately, connected at the inlet and the outlet with two dummy collectors, modelled with two time dependent volumes. The secondary mass flow rate is imposed with four time dependent junctions, one for each operating IHX. The DOTE components are also modelled, closing the inlet junctions to prevent the primary mass flow rate passing through (Giannetti et al., 2018).

The primary pumps are reproduced separately (see Figure 5); each one consists of an ascending pipe, reproducing the annular inlet connected in the correspondent volumes of the cold pool as shown in Figure 6, and a descending pipe, including the pump component. The pump homologous curves are taken from the Phénix reference data (Grosjean et al., 2015). 
Figure 6 shown the radial and azimuthal meshes of the multi-dimensional (MULTID) component that reproduces the pools, the diagrid and the core bypass. It consists of 35 axial levels, 6 radial rings and 15 azimuthal sectors. The diagrid redirects $10 \%$ of the primary mass flow rate to the VCS, reproduced with a pipe component as shown in Figure 5 (Narcisi et al., 2019a).

The Cheng and Todreas correlation is assumed for the evaluation of the pressure drop in the rod bundle (Del Nevo et al., 2016). Two correlations have been implemented in RELAP5-3D for the calculation of the heat transfer coefficient (HTC): the Seban-Shimazaki correlation for non-bundle geometry and the Westinghouse correlation for bundle geometry, developed for a range of $\mathrm{p} / \mathrm{d}$ from 1.1 to 1.4 (The RELAP5-3D ${ }^{\odot}$ Code Development Team, 2015b). Being the IHX p/d equal to 1.43, the Graber-Rieger correlation (Sha et al., 1979) has been selected, correcting the HTC with a constant multiplicative factor, evaluated in nominal conditions and fixed to 1.42 .

The main dimensions of the model are summarized in Table 2.

Table 2 RELAP5-3D model: main dimensions

\begin{tabular}{ll}
\hline Parameters & Quantities \\
\hline Hydraulic volumes & 6940 \\
Hydraulic junctions & 11840 \\
Heat structures & 6888 \\
Heat transfer mesh points & 40170 \\
\hline
\end{tabular}
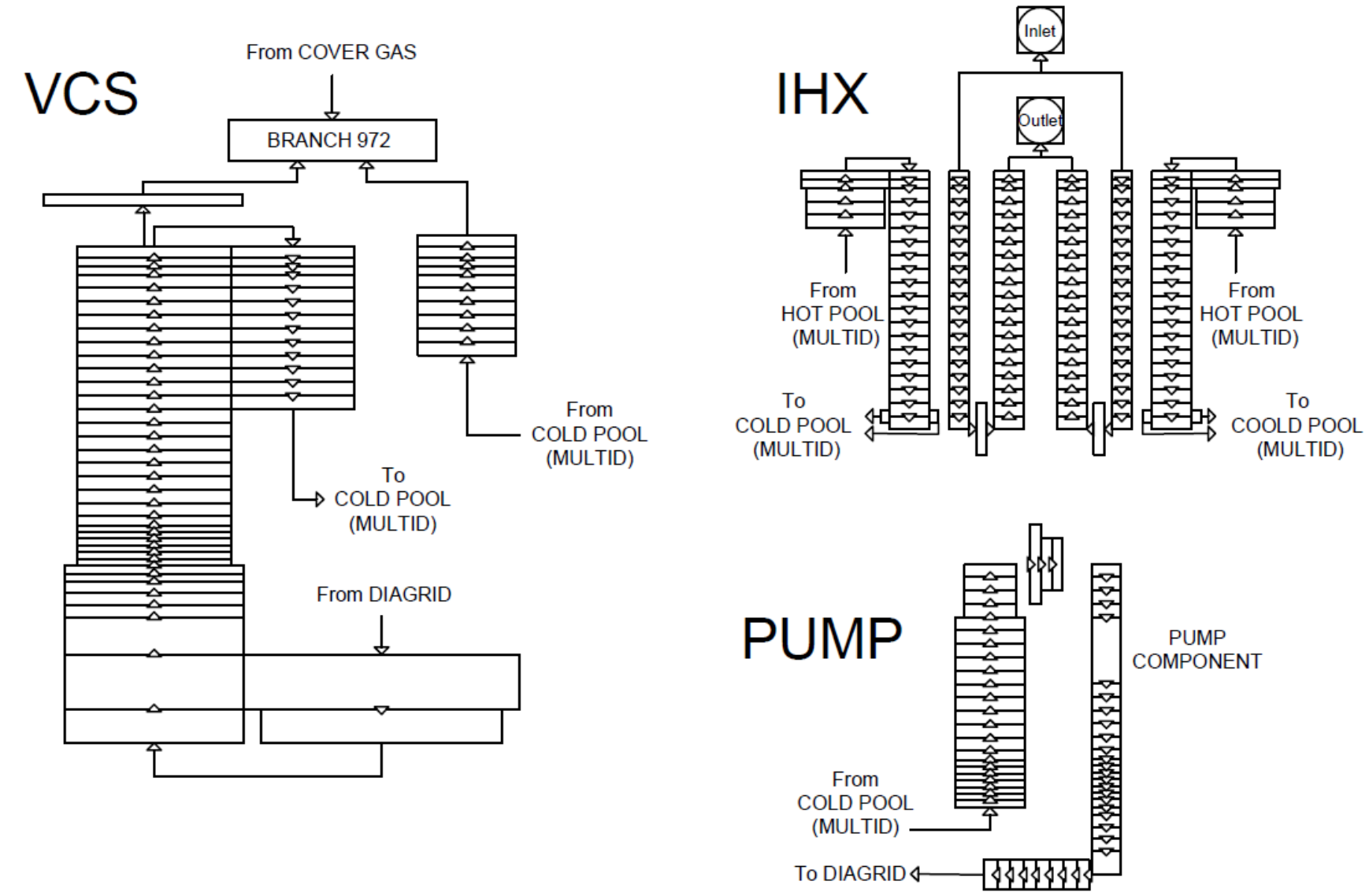

Figure 5 Overview of the RELAP5-3D (1D part) modelling scheme PHÉNIX 


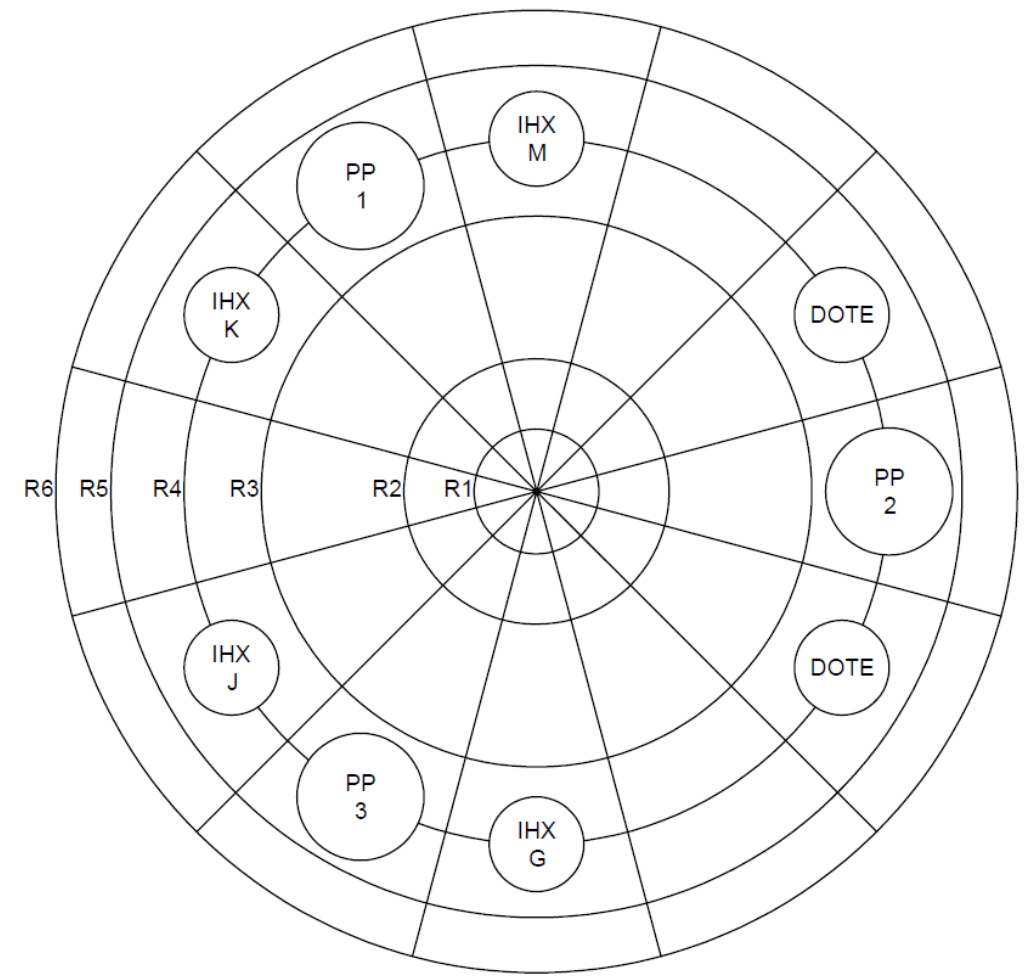

Figure 6 Overview of the RELAP5-3D (3D part) modelling scheme PHÉNIX

\section{KIT model with ATHLET}

The system thermal hydraulic code ATHLET (Analysis of THermal-hydraulics of LEaks and Transients) (Austregesilo et al., 2016) is being developed by the Gesellschaft für Anlagen- und Reaktorsicherheit (GRS). This code is used for analysis of normal operational condition, abnormal transient and leakage accidents in nuclear power plants. The code covers the design basis and beyond design basis accidents (without core degradation). The code can be used for PWR, BWR, SMRs and future generation IV reactors.

In this model, the reactor core is divided into 6 zones, including inner core, outer core, blanket zone, control rod and safety rod zone, in-containment fuel storage zone and steel shielding zone. The 3 primary pumps and 4 intermediate heat exchangers are modeled separately. Each two heat exchangers are coupled with one secondary loop. In the primary loop, $90 \%$ of coolant flows into core, and $10 \%$ is used for vessel cooling. The decay heat of the core is simulated by the user given heat source.

As shown in Figure 7, the pool type reactor is filled with working fluid of sodium, and the top of the system is covered by argon gas. The sodium coolant from the diagrid goes through the reactor core and it is heated by the fuel rods. The thermal power is given as an input in 6 different core zones. After heating by the core, the coolant flows into the hot pool, which is modeled as several big branches and pipes. Then the coolant, from hot pool, is split into 4 intermediate heat exchangers, and the heat is released through thermal conduction to the secondary side. In the secondary side, the time dependent inlet and outlet boundaries are given as input for two secondary loops. Each secondary loop goes into two heat exchangers. After cooling by the 4 heat exchangers, the sodium coolant comes into the cold pool, then it is mixed with the coolant in bottom region, and it flows into the pump inlet skirt, and finally it is pumped back to diagrid again. By the way, about $10 \%$ of the coolant flows from the diagrid into the vessel cooling loop and it enters the cold pool from the surface region. The hot pool, cold pool and vessel cooling pool are connected by the argon layer with the cross connections. The argon gas works like a pressurizer to stabilize the system pressure.

The most important components in the primary loop are the primary pumps. In this model, 3 primary pumps are used to connect cold pool and diagrid. The pump is discretized into several parts. The pump inlet skirt is simulated as pipe component, and the turning point is modeled as a branch, and then it is connected to the pump model, and the pump outlet is also modelled as a pipe connecting to the diagrid. The differential pressure control model is used on the pump component, and the pump speed is given as a constant value of $540 \mathrm{rpm}$. The experimental result gives the pressure difference value $2.09 \mathrm{bar}$, which works as the driving force of the primary loop.

The intermediate heat exchanger is divided into primary side and secondary side; the both sides are connected by the heat conduction object. The heat of coolant is released from the primary side to the secondary side by heat conduction of IHX tubes. In the flow path of secondary side, the downward part is simulated as a vertical pipe, and the flow direction changes to upward from the mixing branch component.

The primary side of the reactor is a closed loop, while the secondary side is an open loop that is used to provide the boundary conditions to the heat exchangers. 


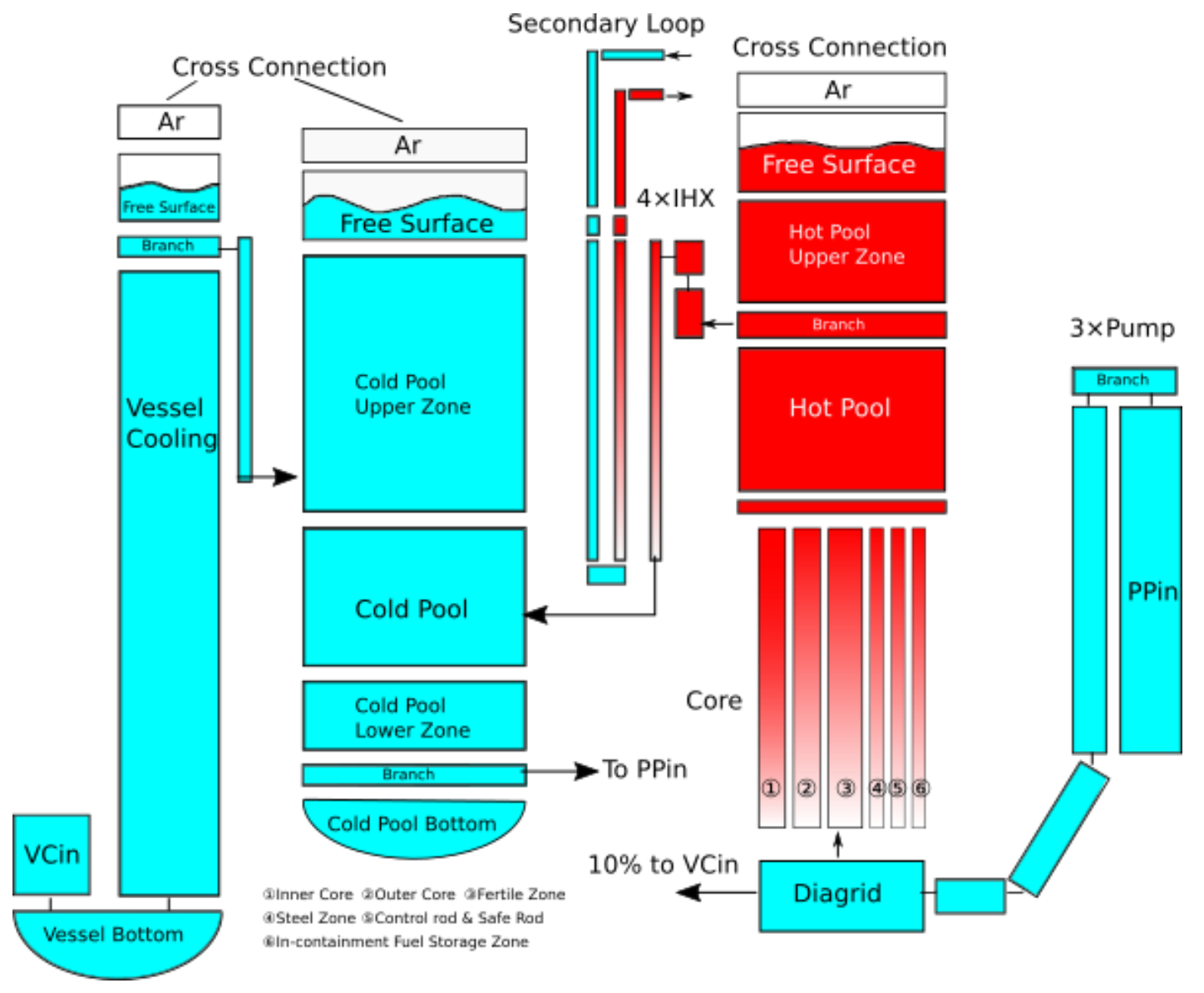

Figure 7 ATHLET model for Phenix

\section{NRG model with SPECTRA}

SPECTRA (Stempniewicz, 2018) is a thermal-hydraulic system code developed at NRG, designed for thermal-hydraulic analysis of nuclear power plants. The code is applicable to Light Water Reactors (LWRs), Liquid Metal-cooled Fast Reactors (LMFRs), High Temperature Reactors (HTRs) and Molten Salt-fueled Reactors (MSRs). Models include multidimensional two-phase flow, non-equilibrium thermo-dynamics, transient heat conduction in solid structures, and a general heat and mass transfer package with built-in models for steam/water/non-condensable gases, including natural and forced convection, condensation, and boiling.

The SPECTRA model of Phénix consists of the following systems:

- $\quad$ Primary system (core, sodium pool, pump, heat exchanger - primary side);

- Intermediate system (heat exchanger - secondary side - with boundary conditions).

Table 3 SPECTRA STH model: hydraulic components

\begin{tabular}{ll}
\hline Parameters & Quantities \\
\hline Hydraulic volumes & 407 \\
Hydraulic junctions & 452 \\
Heat structures & 309 \\
Heat transfer mesh points & 2565 \\
\hline
\end{tabular}

The sodium coolant is modelled as an external coolant with tabulated user-defined thermo-physical properties, for the sole liquid phase, according to the correlations provided in (Fink et al., 1995). Solid structures are defined to model heat transfer and heat capacity in the system. The following materials are implemented:

- $\mathrm{MOx}$ - for fuel pin pellets (20.54 tons);

- $\quad$ Stainless steel AIM1 - for the internal structures in the pool, the IHX tubes and the fuel pin cladding (582.3 tons);

- Stainless steel 316 - for the rods of the shielding elements (138.8 tons);

- Graphite - for the internal part of the logs (56.00 tons).

Alcaro and Doolaard (2018) provide full details of the sodium and solid structures material properties. The overall inventory of sodium in the primary system is 800.8 tons. 
The nodalization scheme adopted for the STH SPECTRA model of Phénix was tailored for the coupled STH/CFD calculations, in the sense that relatively coarse nodalization is adopted for the model of the large pool regions. A summary of the components adopted is provided in Table 3. The nodalization of Phénix was conceived to account for three azimuthal sectors, corresponding to the three sets of primary pumps and IHXs couples. Therefore, the hot pool, cold pool, diagrid and core are each split in three (symmetric) azimuthal sectors. The nodalization scheme of the pool is presented in Figure 8 , for the azimuthal sector 1 only. The logs are modelled as filled rods in contact with the hot pool (at the same level of the core assemblies). The overall inventory of sodium in the cold and hot regions is respectively 522.92 tons and 251.94 tons. The hot and cold pool surfaces are connected to a fixed-properties volume representing the pressure control of the Argon cover gas. A pressure of 1 bar is adopted. In order to obtain the requested flow in the vessel cooling bypass during nominal steady-state conditions ( $10 \%$ of the total primary pump flow) a form loss factor in the vessel cooling bypass outlet junction was tuned for the purpose (JN-404, see Figure 8). Convective heat transfer between the sodium and vessel walls, i.e. hot pool/cold pool vessel, external vessel and internals, is calculated according to the Lyon correlation (Lyon, 1951).

The nodalization scheme of the core assemblies is presented in Figure 9, for the azimuthal sector 1 only. All assemblies except from the blanket, the reflector and the shielding elements are modelled as a single type (left picture of Figure 9). The gap conductance in the fuel and blanket rods is user-defined according to source data provided by CEA (Grosjean et al., 2015). Figure 10 illustrates the nodalization scheme of the active region of the fuel and blanket rods.

The pressure losses in the core assemblies are due to:

- A form loss factor representing losses due to flow restrictors;

- A form loss factor representing losses due to assembly inlet;

- A form loss factor representing losses due to assembly outlet;

- Wall friction through the rod bundle.

Inlet/outlet loss factors correspond to abrupt area change (from/to infinitely large volume). Flow restrictor loss factors were tuned in order to obtain the specified core losses under nominal steady-state conditions, according to source data provided by CEA (Grosjean et al., 2015). Wall friction in the rod bundle (turbulent regime) is internally calculated by SPECTRA as the maximum value of the friction factor resulting from the Blasius and the Prandtl-Nikuradse (Nikuradse, 1936) formulae. Heat transfer in the fuel bundle is calculated by means of the Mikityuk correlation (Mikityuk, 2009).

The nodalization scheme of the IHX is given in Figure 11, for the IHX-K only. The model is the same for the other three IHXs. The IHX are modelled as insulated from the hot pool, i.e. no wall of the IHX shroud is accounted for. The total heat transfer area, calculated at the outer diameter boundary of the IHX tubes, is $537.764 \mathrm{~m}^{2}$ for each IHX and stems from the number of tubes, the tubes outer diameter and the heated length provided by CEA (Grosjean et al., 2015). Form loss factors were imposed on the primary side inlet and outlet in order to obtain the specified IHX losses under nominal steady-state conditions, according to source data provided by CEA (Grosjean et al., 2015). Wall friction in the tube bundle is calculated as described for the assemblies rod bundle. The secondary side of the IHX is modelled consistently (in terms of axial nodalization) with the primary side. The central downcomer pipe wall is not modelled; therefore, the primary-to-secondary heat transfer occurs only through the HX tubes. The correlation adopted is the Mikityuk correlation. Boundary conditions are tabulated, in particular:

- Secondary sodium temperature is imposed for the inlet volume (CV-590 of left picture in Figure 11);

- Secondary sodium pressure is imposed for the outlet volume (CV-599 of left picture in Figure 11);

- Secondary sodium mass flow rate is imposed at the inlet junction volume (JN-590 of left picture in Figure 11).

The nodalization scheme of the primary pump accounts for the inlet skirt and the outlet pipe. The arrangement of the primary pump is given in Figure 8, for PP-1 only. The model is the same for the other two pumps. Form loss factor were imposed on the skirt inlet and discharge outlet in order to obtain the specified pump and LIPOSO losses under nominal steady-state conditions, according to source data provided by Grosjean (2015). No solid structures are used to model the pump case, therefore no heat losses with the cold pool are accounted for. The SPECTRA model of the pump includes a mechanistic model that is based on the available homologous curves provided by CEA. Alcaro and Doolaard (2018) provide full details of the characteristic curve of the primary pumps adopted in the SPECTRA model. 


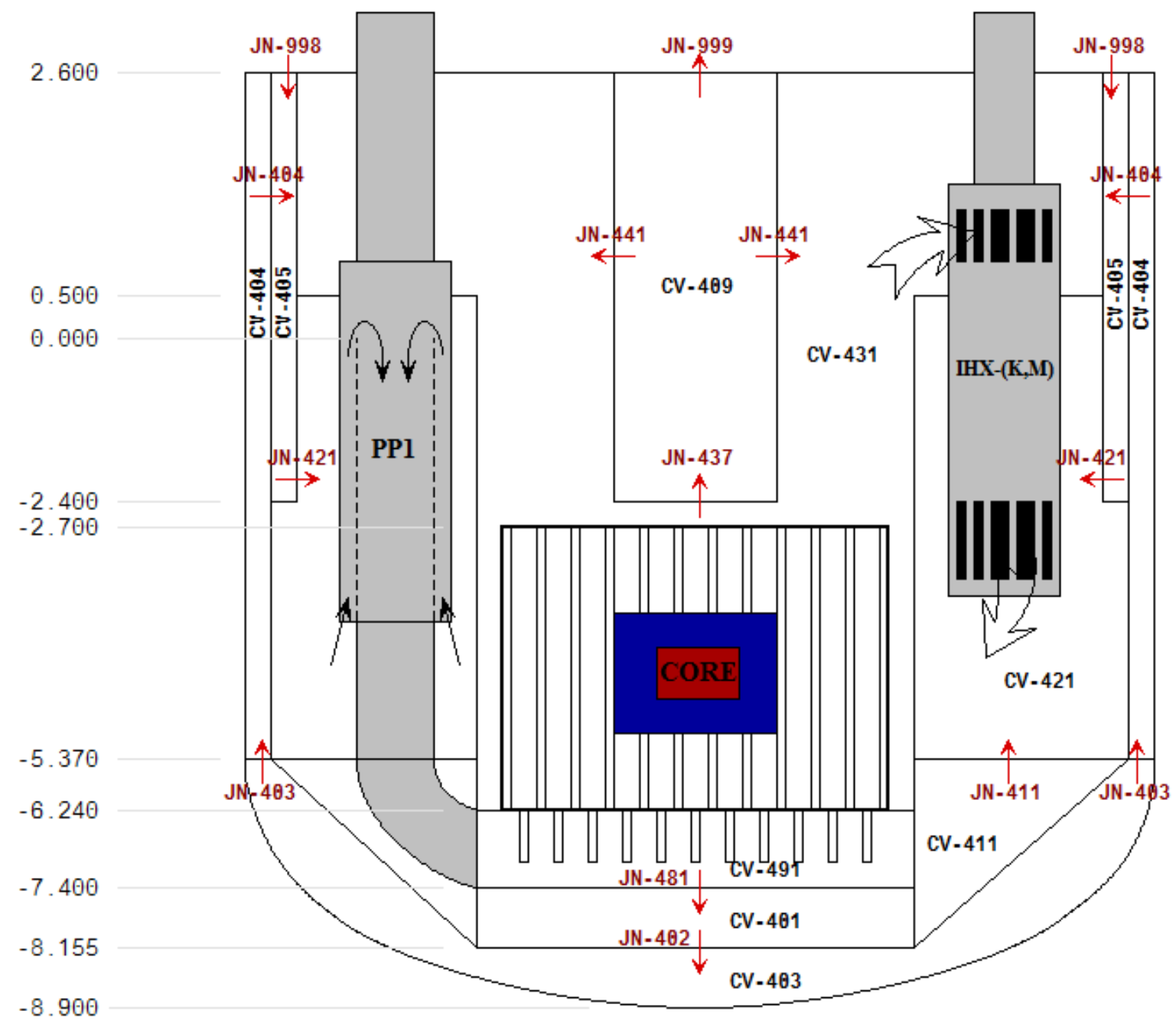

Figure 8 Nodalization scheme of the sodium pool - single azimuthal sector

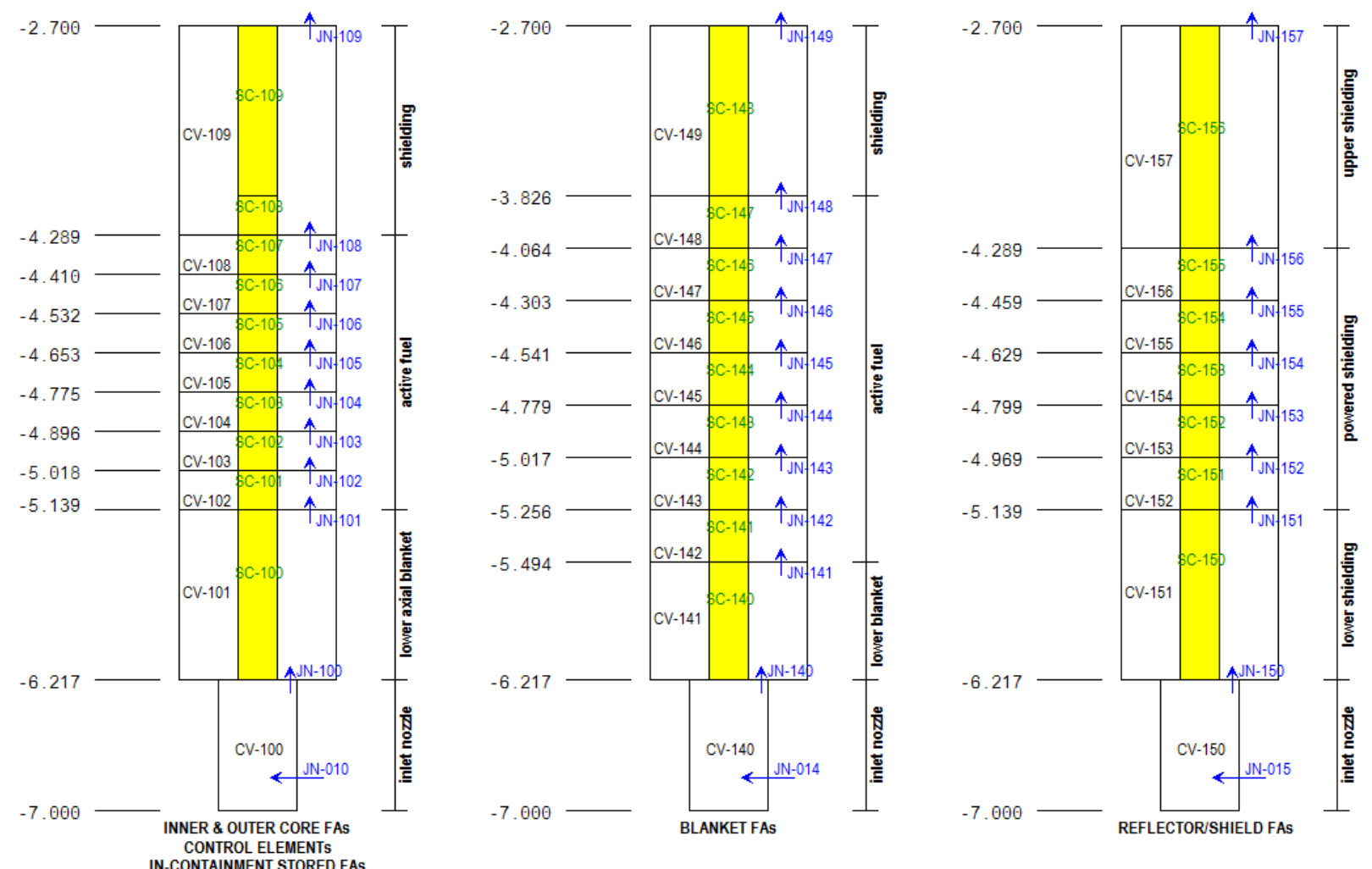




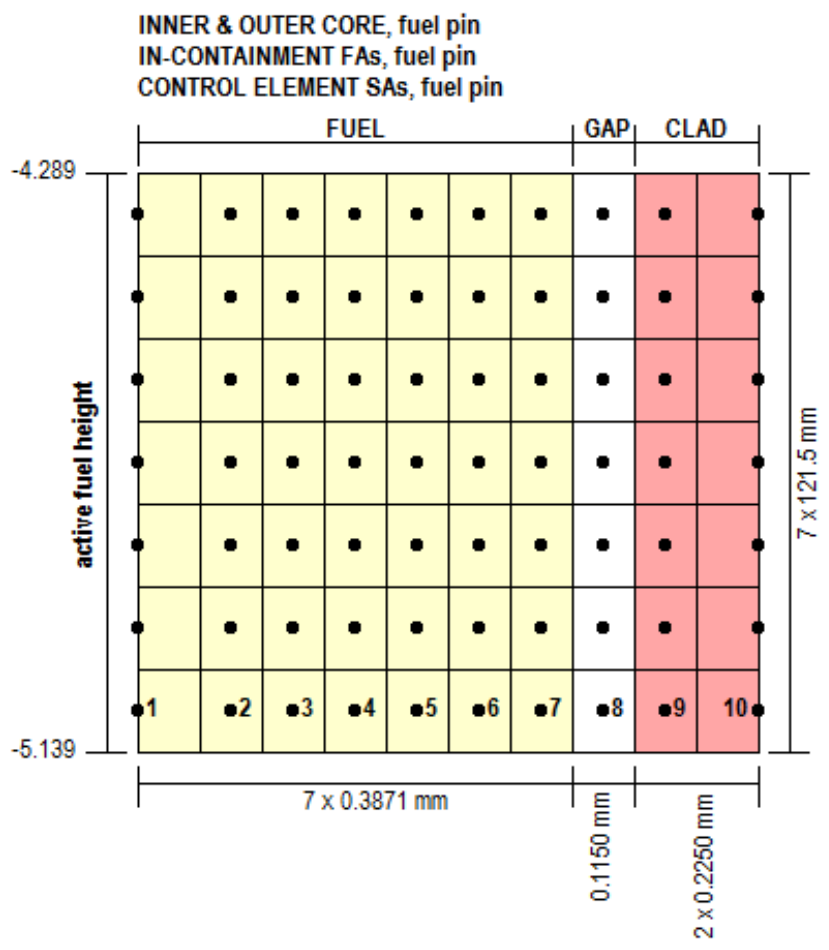

Figure 10 Nodalization of the fuel pins of the Phénix core

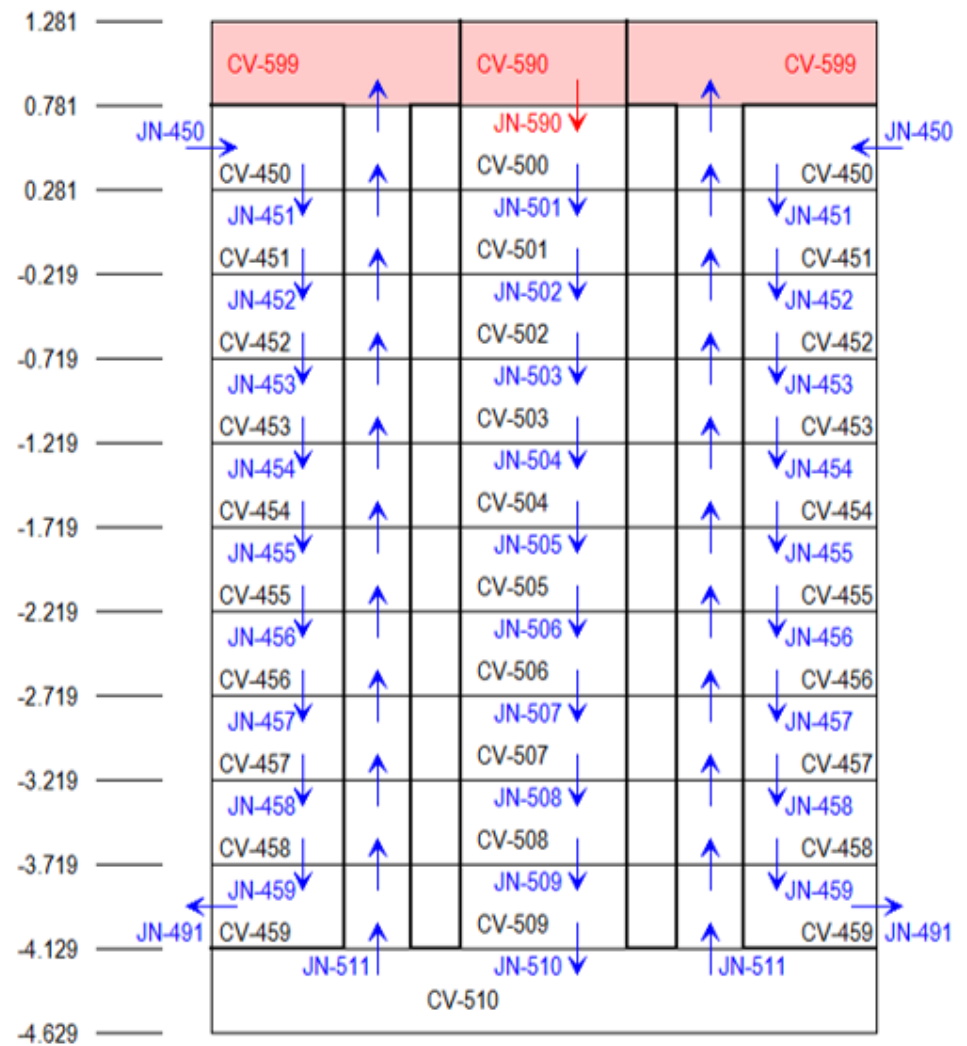

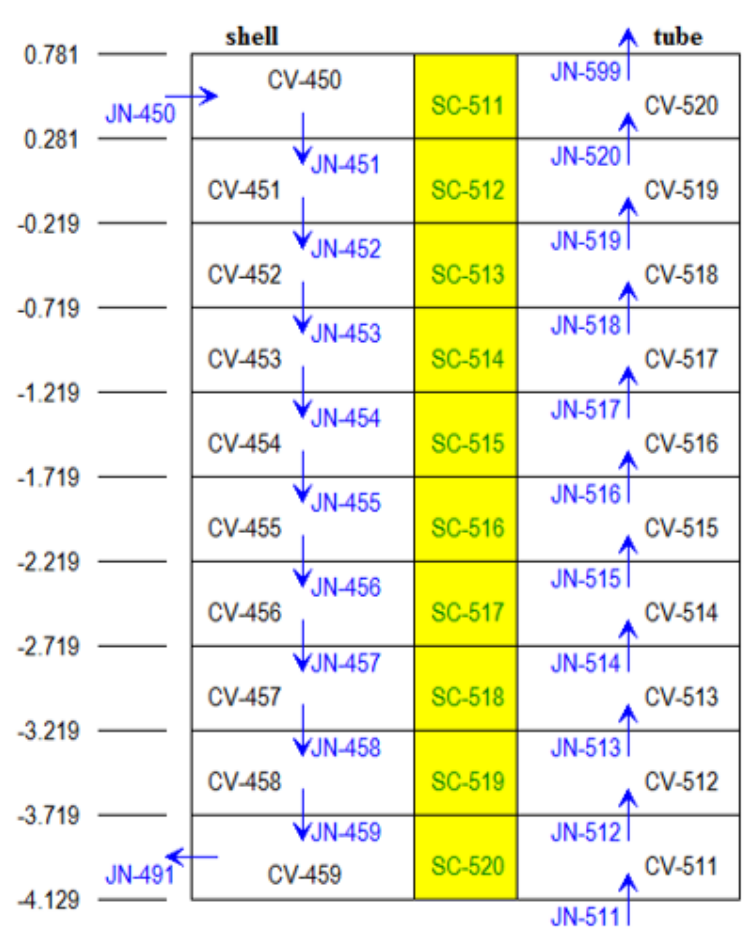

Figure 11 Nodalization scheme of the IHX-K (left) and tube details (right) 


\section{ARGONNE model with SAS4A/SASSYS-1}

The SAS4A/SASSYS-1 version 5.2.2, the liquid-metal cooled reactor safety analysis code developed and maintained by Argonne National Laboratory (Fanning et al., 2017), was utilized to develop a model of the Phénix reactor and coolant systems. The core model consists of five separate channels that correspond to each of the five flow zones in the core as specified by CEA (Grosjean et al., 2015), including the inner core, outer core, blanket, and reflectors and control rods, and fuel storage (SAS4A/SASSYS-1 does not currently maintain the capability for direct specification of above-core fuel storage). Core inlet orifice coefficients were adjusted to obtain the specified pressure drop across the core for steady-state conditions.

The models of the primary and secondary sodium coolant systems, as seen in Figure 12, are based on the data provided by CEA. Flow enters the core from the inlet plenum $\left(\mathrm{CV}_{1}\right)$, is heated in the core, and then enters the hot pool $\left(\mathrm{CV}_{2}\right)$. The hot sodium is driven into the shell side of the intermediate heat exchangers $\left(E_{2}-E_{5}\right)$ and cooled sodium returns to the uppermost cold pool $\left(C_{3}\right)$. The cold pool was nodalized into three volumes in an effort to capture flow stagnation and the resulting thermal gradients in the uppermost and lowermost cold pool regions. Segments connecting these cold pool CVs are treated as having negligible thermal mass. The three primary pumps $\left(E_{7}, E_{10}\right.$, and $\left.E_{13}\right)$ force sodium to return from the lower cold pool to the inlet plenum. The vessel-cooling system is modeled with annular flow elements $\left(\mathrm{E}_{18}\right.$ and $\left.\mathrm{E}_{19}\right)$ that may transfer heat from the cold pool volumes. This model does not treat the open nature of the vessel-cooling circuit, however this modeling decision is considered to have negligible impact on overall system behavior. Nodalization details of the primary system are provided in Table 4.

Four intermediate heat exchangers and three primary pumps were explicitly modeled for this test in an effort to capture the asymmetric transient trends via CFD coupling. Segment orifice coefficients for the vessel cooling network were adjusted to obtain a flow rate through the vessel cooling network that approximately matched the benchmark specification. The vessel-cooling system is modeled with annular flow elements that transfer heat from the cold pool volume and to the environment at their approximately nominal rates $(0.05 \%$ and $0.1 \%$, respectively). Compressible volumes employ a perfect mixing model. The cold pool was nodalized into three volumes in an effort to capture flow stagnation and the resulting thermal gradients in the uppermost and lowermost cold pool regions. Heat transfer between the hot and cold pools was included at an estimated nominal rate of $1.5 \%$, and heat rejection from the head was included at the specified nominal rate of $\sim 0.05 \%$.

Table 4: SAS4A/SASSYS-1 Primary System Nodalization Characteristics

\begin{tabular}{|l|c|}
\hline Parameter & Quantities \\
\hline Compressible Volumes & 6 \\
\hline Liquid Flow Segments & 13 \\
\hline Liquid Flow Elements & 21 \\
\hline Temperature Groups & 17 \\
\hline Nodes & 405 \\
\hline
\end{tabular}

All pumps in the primary and secondary systems are treated as homologous pumps, which allows for direct specification of pump speed as a function of time. The secondary systems are modeled with sufficient detail to enable specification of the benchmark boundary conditions and system parameters. Secondary system flow rate boundary conditions were applied as a normalized pump speed in the secondary loops, and primary pump speed for all three pumps was held constant throughout the transient simulation. Secondary loop inlet temperature boundary conditions were specified as a steam generator outlet temperature. Because normalized core power was included as part of the benchmark specification, the point kinetics feature of SAS4A/SASSYS-1 was not utilized. 


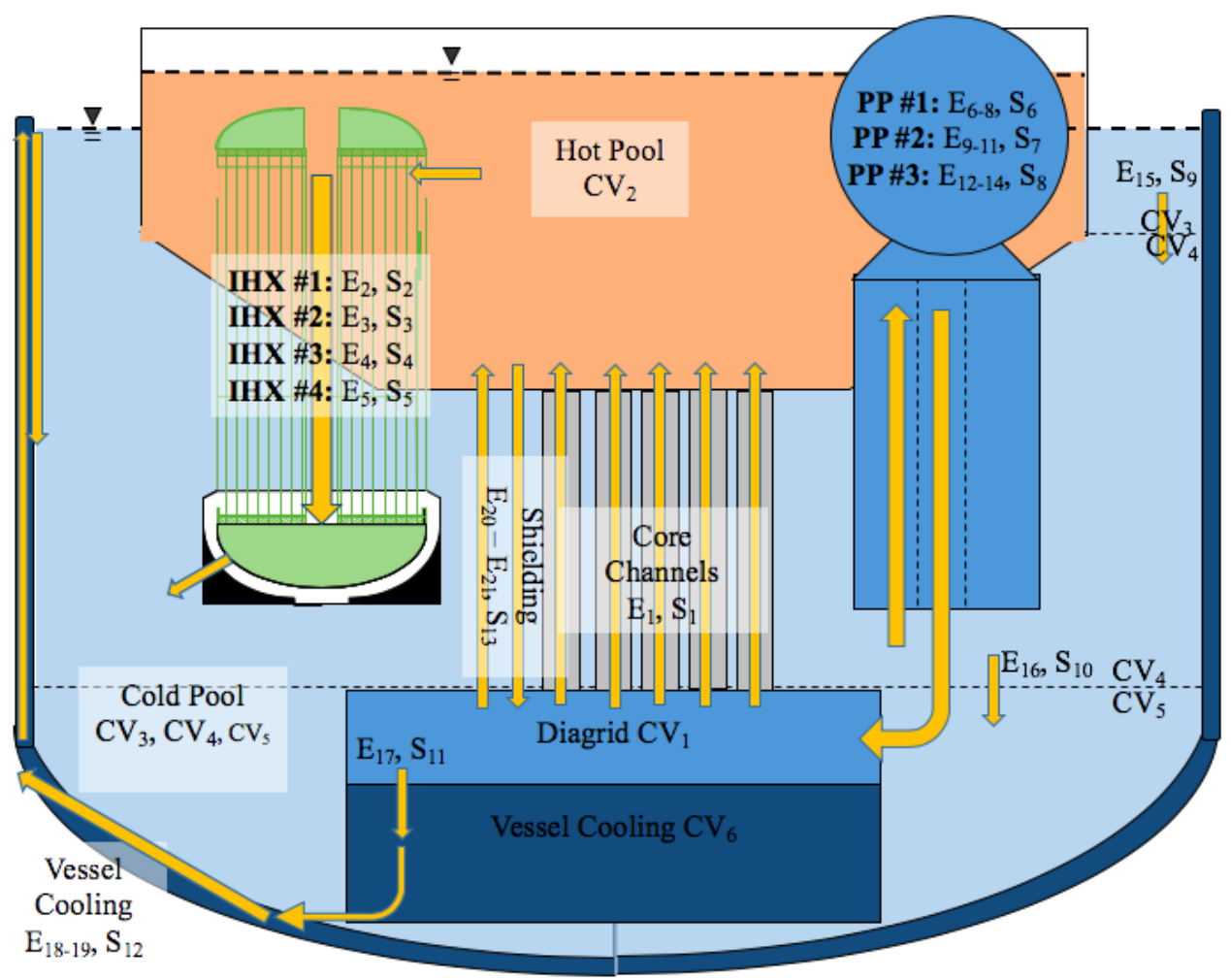

Figure 12 Schematic of SAS4A/SASSYS-1 Model of the Phénix Primary Coolant System

\section{IRSN model with ASTEC-Na}

ASTEC-Na is based on V2.1 version of the calculation code system ASTEC (Accident Source Term Evaluation Code) (Chatelard et al., 2016) (Chailan et al., 2017), developed since 2009 by IRSN to simulate the whole scenario of a severe accident in sodium-cooled fast reactors (SFRs) from the initiating event in the core up to radiological releases of fission products into the environment (Girault et al., 2013). The modular ASTEC V2 code structure is composed of several modules (each simulating a reactor zone or a set of physical phenomena) which communicate with each other through a dynamic memory for data exchange at macro-time steps. Both stand-alone mode for running each module independently and coupled mode where all (or a subset) of the modules are run sequentially within a macro-time step can be used.

From a thermal-hydraulic point of view, the CESAR (Circuit Evolution during a Severe Accident in a Reactor) module computes the sodium single and two-phase thermal-hydraulics in the whole reactor vessel (core, primary and secondary circuits). The space discretization in CESAR applies the staggered grid with the mass and energy conservation equation defined in volumes and the momentum balance equation defined in junction. A 2D version can be used to support a radial/axial discretization of the core region and simulating in-core 2D two-phase flow patterns.

The thermal-hydraulic modelling in CESAR is based on a two-fluid 5-equation approach which means that 5+N differential equations ( $\mathrm{N}$ being the number of non-condensable gases) and 1 algebraic equation need to be solved ( $2+\mathrm{N}$ mass differential balance equations, 2 energy differential balance equations, 1 mixture differential momentum balance equation and 1 algebraic equation which models the interfacial drag between the liquid and the gas phase. Thermal and mechanical non-equilibrium can be considered between phases. The numerical method used in CESAR follows the finite volume technique. The time integration is performed using a Newton's method and applying a fully implicit scheme.

The main developments that were made respectively in CESAR to model sodium-cooled reactors include:

- Sodium fluid properties issued from Fink and Leibowitz (1995) and SIMMER code,

- Specific heat transfer relations for the description of the complete sodium boiling curve (convection/ critical heat flux correlations, transition criteria between the different regimes....). More especially, within the convection regime, five different correlations are available to calculate the Nusselt number depending on the structure geometry (tubular/bundle, pitch-to-diameter ratio...) and the thermal-hydraulic characteristics (Pe number),

- Specific friction loss coefficients in the fuel pin zone to take into account wire-wrapped pin bundles were also implemented (Novendstern correlations (Novendstern, 1972)).

The ASTEC-Na model of the Phénix reactor includes the core, the entire primary sodium circuit and a simplified description of the secondary sodium circuits. This latter is modelled as an open circuit that is used to provide the boundary conditions for the heat exchangers. 


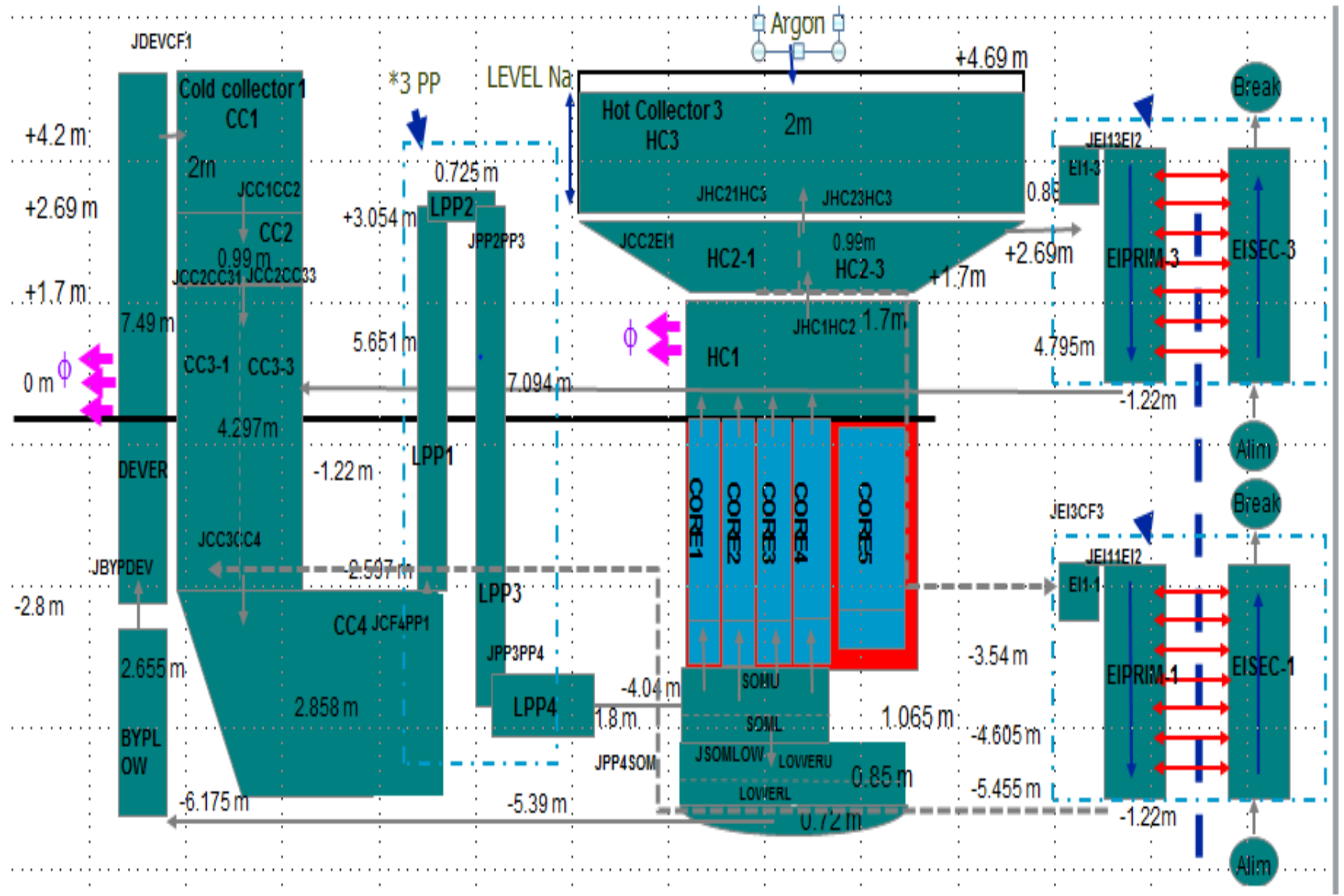

Figure 13 ASTEC-Na model for PHÉNIX reactor

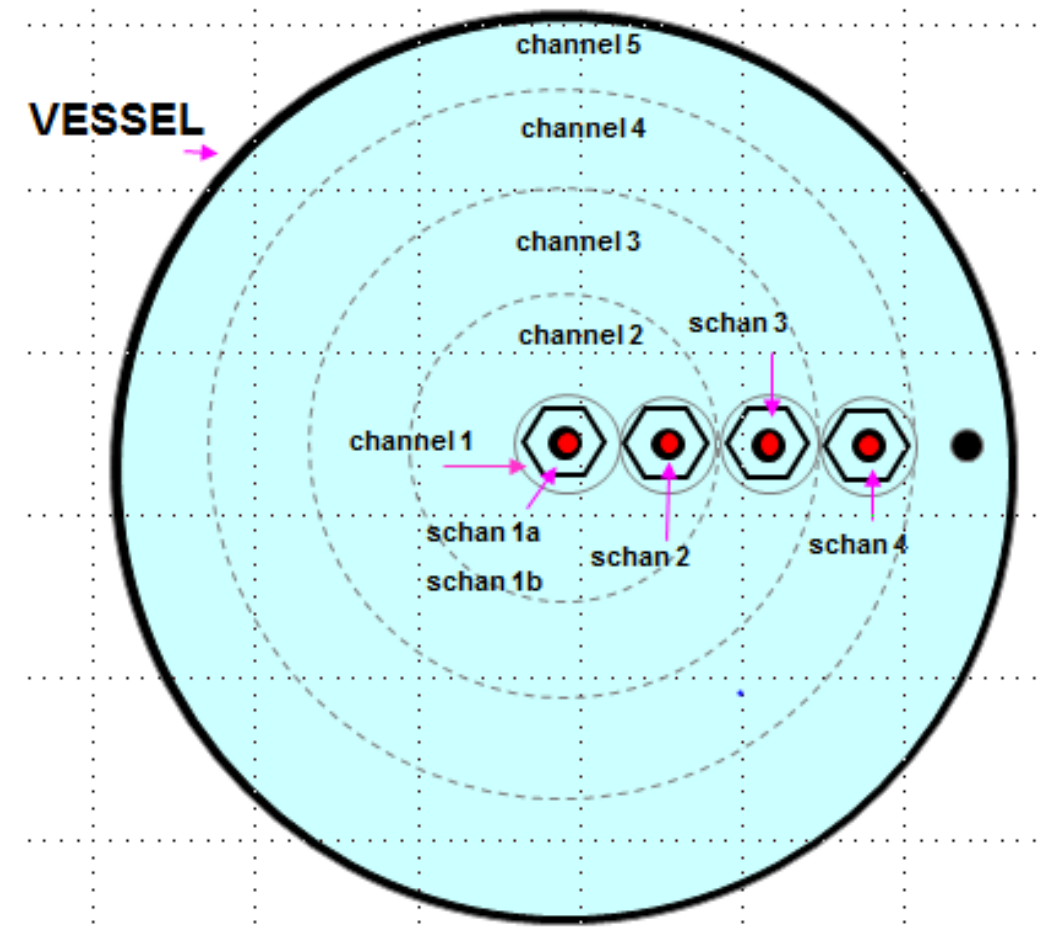

Figure 14 Core multi-channel modelling

As seen in Figure 13, the most important components of the reactor vessel were modelled as following:

○ Primary pumps and discharge lines: four 1D volumes. Only one pump with a weight of three was considered and one single homogeneous cold collector volume corresponding to the three pump inlets. It means that the asymmetrically 
behavior in the pump inlet/top temperatures measured at the beginning of the transient will not be captured by the calculations;

- Primary sides of the intermediate heat exchangers: two homogeneous 0D volumes and a meshed volume composed of 20 meshes. The two sides are connected by a wall involving that the heat transfer from the primary side of the IHX to the secondary side takes also into account the heat conduction through the IHX tubes. Only two IHXs (one per secondary loop) were modelled with a weight of 2 ;

○ Cold pool and hot pool: respectively five and three 0D homogeneous volumes with the $3^{\text {rd }}$ volume of the cold pool, corresponding to IHX outlets and the $2^{\text {nd }}$ volume of the hot pool, corresponding to the IHX inlets, being divided radially in two different volumes. Heat exchanges between both pools were calculated by conduction through the internal primary vessel;

- Lower plenum and diagrid: $0 \mathrm{D}$ volumes where singular head losses were imposed at the lower plenum inlet to match the steady-state mass flow rate in the reactor vessel cooling system.

The ASTEC-Na core meshing used a multi-channel description. Five parallel 1D sub-channels were used in which fuel subassemblies were represented by an average representative subassembly (Figure 14), numerically weighted to model a group of fuel assemblies located in the same core area. In addition, the core was discretized into five different axial parts corresponding to the lower/upper plenum, to the lower/upper fertile blankets and to the fissile part with respectively $4 / 6,6 / 7$ and 17 meshes.

The initial pump speed was imposed at $690 \mathrm{~kg} / \mathrm{s}$, leading to an initial primary flow rate of about $2230 \mathrm{~kg} / \mathrm{s}$. The calculated pump pressure loss was about 2.1 bars. The default heat transfer correlation for convection was used (Mochizuki and Takano, 2009) and no specific friction loss coefficients in the core were taken into account. Inlet boundary conditions of flow rates and temperatures were imposed for the secondary side of the IHXs and an outlet conditions fixing the pressure at the top of the IHX ( 3 bars) was also used. During the steady-state calculations, the axial singular pressure losses were adjusted for each core sub-channel inlet in order to match the steady-state coolant mass flow rate distribution in the core (Table 1). No radial pressure losses were considered.

Table 5 Axial pressure loss coefficients

\begin{tabular}{llllll}
\hline SUB CHANNEL & SSCORE1a & SSCORE1b & SSCORE2 & SSCORE3 & SSCORE4 \\
\hline k_e & 0.201 & 33 & 0.18 & 10.3 & 410 \\
\hline
\end{tabular}

\section{RESULTS}

All the participants performed a first calculation to obtain the steady state results which were identified as the initial conditions for the transient test. The boundary conditions and the main steady state results are summarized in Table 6 . The boundary conditions used by the participants were the core thermal power, the sodium inlet temperature on the IHXs secondary side (SS) and the secondary mass flow rate (MFR). In addition, IRSN imposed the total primary pump MFR, as introduced in the previous section.

The comparison with the experimental data (Ref. Data in Table 6) highlights a good prediction for all the participants, despite the not equal thermophysical properties used for each code. The differences in the mean specific heat (evaluated using the core values from Table 6) is, for instance, an important source of uncertainties. The minimum differences versus the experimental data are found for CATHARE and R5-3D (4\% and 6\% respectively) and the main differences are evaluated for ATHLET and SAS4A/SASSYS-1 (16\% and $14 \%$ respectively). Then, considering that the power is an indirect measure affected by a large experimental uncertainty, some participants modified the power boundary condition to reach the right mass flow rate and temperatures conditions in the primary circuits.

The deviation between experimental data and calculated values are less than 5\% for most of the quantities, except for the IHX primary outlet temperature, slightly overestimated with CATHARE calculations (10\%), and the mass flow rate through the VCS, underestimated with ATHLET (-28\%) and overestimated with SAS4A/SASSYS-1 and ASTEC-Na.

\begin{tabular}{|c|c|c|c|c|c|c|c|c|}
\hline QUANTITY & Unit & Ref. Data & $\begin{array}{c}\text { CEA } \\
\text { CATHARE }\end{array}$ & $\begin{array}{l}\text { UNIROMA1 } \\
\text { RELAP5-3D }\end{array}$ & $\begin{array}{c}\text { KIT } \\
\text { ATHLET }\end{array}$ & $\begin{array}{c}\text { NRG } \\
\text { SPECTRA }\end{array}$ & $\begin{array}{c}\text { ARGONNE } \\
\text { SAS4A/SASSYS-1 }\end{array}$ & $\begin{array}{c}\text { IRSN } \\
\text { ASTEC-Na }\end{array}$ \\
\hline Core power & MW & 341 & 326 & 341 & 351.7 & 341 & 341 & 352 \\
\hline SS IHX inlet T & $\mathrm{K}$ & 594 & 593 & 594 & 593 & 594 & 594 & 595 \\
\hline SS IHX MFR & $\mathrm{kg} / \mathrm{s}$ & 347 & 347 & 347 & 345 & 347 & 341 & 349 \\
\hline PP total MFR & $\mathrm{kg} / \mathrm{s}$ & 2209 & 2167 & 2211 & 2136.7 & 2247 & 2186 & 2232 \\
\hline SS IHX outlet T & K & 784 & 781 & 787 & 792 & 786 & 786 & 791 \\
\hline Core inlet $\mathrm{T}$ & K & 655 & 656 & 660 & 658 & 655 & 659 & 661 \\
\hline Core outlet T & K & 807 & 796 & 806 & 798 & 789 & 794 & 800 \\
\hline PS IHX inlet T & K & 793 & 790 & 792 & 798 & 787 & 792 & 796 \\
\hline PS IHX outlet T & K & 658 & 696 & 660 & 658 & 654 & 658 & 661 \\
\hline Core MFR & $\mathrm{kg} / \mathrm{s}$ & 1988 & 1946 & 1992 & 1978.6 & 2006 & 1988 & 1988 \\
\hline
\end{tabular}


Nuclear Engineering and Design 353 (2019) 110272, https://doi.org/10.1016/j.nucengdes.2019.110272

\begin{tabular}{ccccccccc} 
MFR VCS & $\mathrm{kg} / \mathrm{s}$ & 221 & 221 & 219 & 158.1 & 242 & 198 & 244 \\
PS IHX MFR & $\mathrm{kg} / \mathrm{s}$ & 497 & 486 & 498 & 496.5 & 501 & 496 & 497 \\
\hline
\end{tabular}

Assuming steady state results as initial conditions, the participants carried out transient simulations, imposing the dissymmetric test boundary conditions. The transient starts with the fast MFR decrease in loop 1 (L1) that leads to a rapid reduction of the power removed by IHX-K and IHX-M. After $5 \mathrm{~s}$, the mass flow rate through secondary loop 3 (L3) starts to decrease slower, causing an asymmetrical condition inside the primary system. All the participants reproduce the decrease of the secondary MFR imposing boundary conditions, leading to a good prediction of the power removed by the two systems, as shown in Figure 15 . The power removed by L1 rapidly decreases in the first $30 \mathrm{~s}$, when the $85 \%$ of the total power is removed by L3 (Figure 16 ). Then, the symmetrical distribution of the power is completely restored at $200 \mathrm{~s}$.
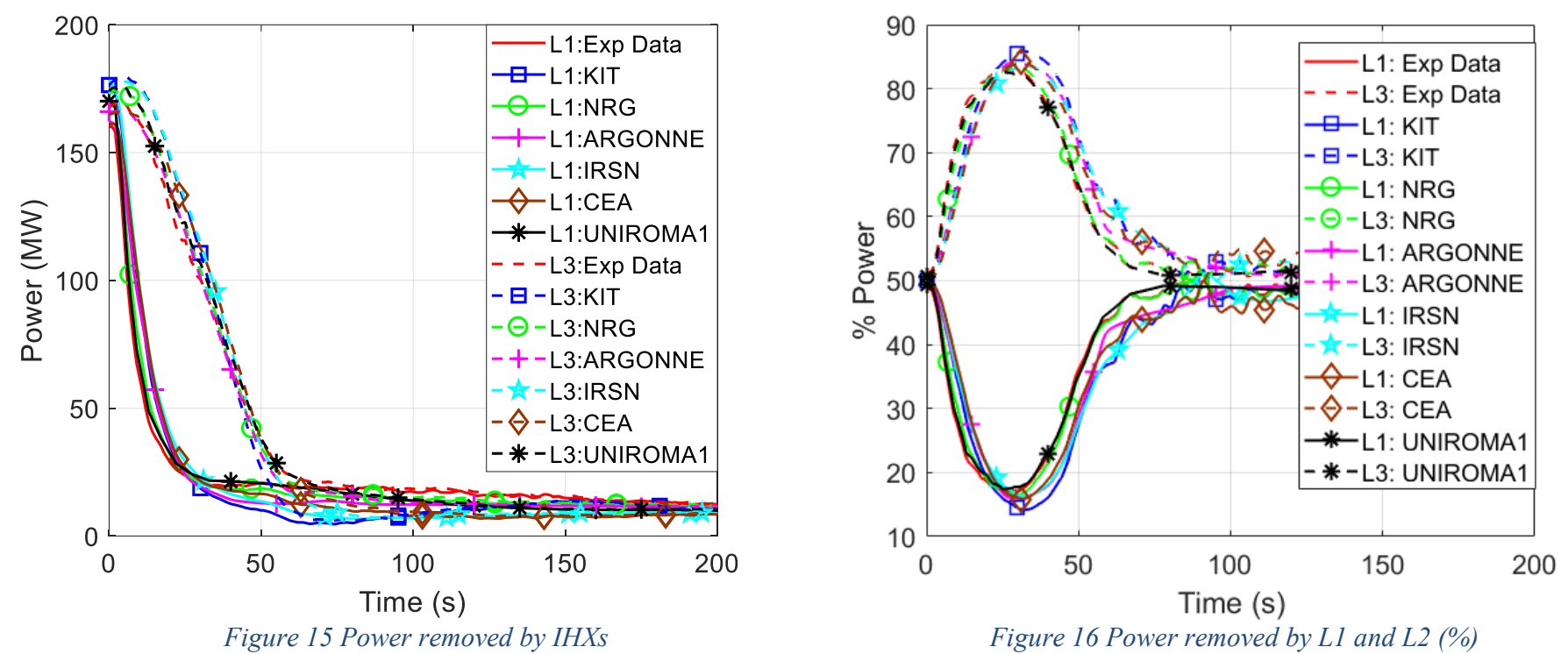

The temperature measurement points used for this benchmark are listed below:

- $\quad$ at the PP1, PP2 and PP3 inlet (measured at the top of the pump skirt);

- $\quad$ at the IHXs K, J and G, on the primary side inlet;

- at the outlet of IHX M;

- at the core outlet.

The quick decrease of the power removed by L1 leads to a hot shock at the IHX-M and IHX-K primary side. Figure 17 shows the comparison of the IHX-M outlet temperature. The experimental temperature reaches a peak value of $766 \mathrm{~K}$ at $35 \mathrm{~s}$, well predicted by the codes. CATHARE and ASTEC-Na highlight a maximum temperature overestimation of $25 \mathrm{~K}$, following the discrepancy obtained with the steady state simulations.

The hot shock at the IHX-J and IHX-G occurs with a delay time due to the slower speed decrease of the secondary pump on L3. The consequence is an asymmetrical distribution of the temperature inside the cold pool. At the beginning of the transient, the inlet temperatures of the primary pumps are equal; after the starting event, the hot sodium exiting the IHX-K and IHX-M reaches the inlet section of the PP1, leading to the peak temperature highlighted by the experimental data ( $664 \mathrm{~K}$ at $50 \mathrm{~s})$. The further increase of the IHX outlet temperature, resulting in a density decrease, leads the hot sodium to the upper part of the cold pool and the cold sodium is moved by the PP1. After $60 \mathrm{~s}$, all the primary pumps inlet temperatures increase, maintaining the PP1 inlet colder than the other two. The maximum temperature of $704 \mathrm{~K}$ is reached in the three primary pumps inlet and then the temperature decreases uniformly. The primary pumps inlet temperatures are compared in Figure 18, Figure 19 and Figure 20. As described, the inlet temperatures are related to the three-dimensional sodium paths in the cold pool. Being the simplified nodalization scheme, ASTEC-Na model is not able to reproduce the dynamics and the amplitude of the temperature increase. The calculated increase of inlet pump temperature occurs quite early and the maximum predicted increase is lower than the experimental data of about $15^{\circ} \mathrm{C}$. The relatively coarse nodalization adopted to simulate the pools in SPECTRA model, leads to a discrepancy during the increase of the PP inlet temperatures. The peak temperature is well predicted but delayed of about $60 \mathrm{~s}$. The other codes well reproduce the first minutes of the ramp, but they highlight discrepancy in the maximum temperature, showing two consecutive peaks in RELAP5-3D and ATHLET simulations instead of the single experimental peak and an overestimation of about 10 degrees in CATHARE and SAS4A/SASSYS-1 calculations. Due to the detailed nodalization of the cold pool, RELAP5-3D predicts a peak temperature at the PP1 during the first minutes of the test; the MULTID component is able to reproduce buoyancy effects inside the cold pool, even if the peak is predicted earlier and with a lower temperature of $4 \mathrm{~K}$ (see Figure 18). A similar peak is also predicted at the inlet of the PP3 (see Figure 20), following the hot shock at the IHX-J and IHX-G and this feature was not detected in the experiment, but it is also observed in all the CFD coupled simulations (Uitslag-Doolaard et al., in this issue). At the end of the test, some discrepancies are highlighted between the measured data and the calculations. 


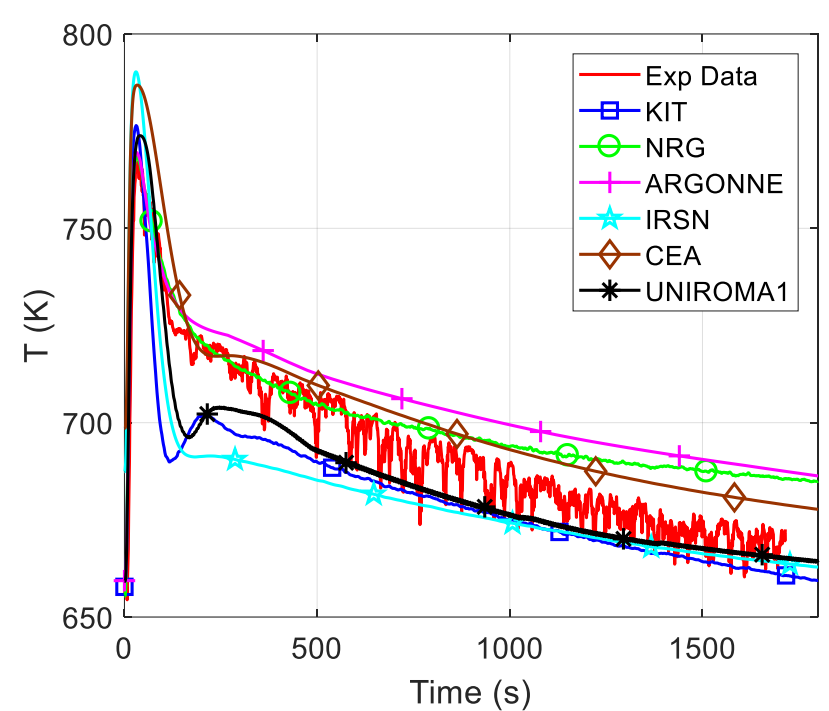

Figure 17 IHX-M outlet temperature

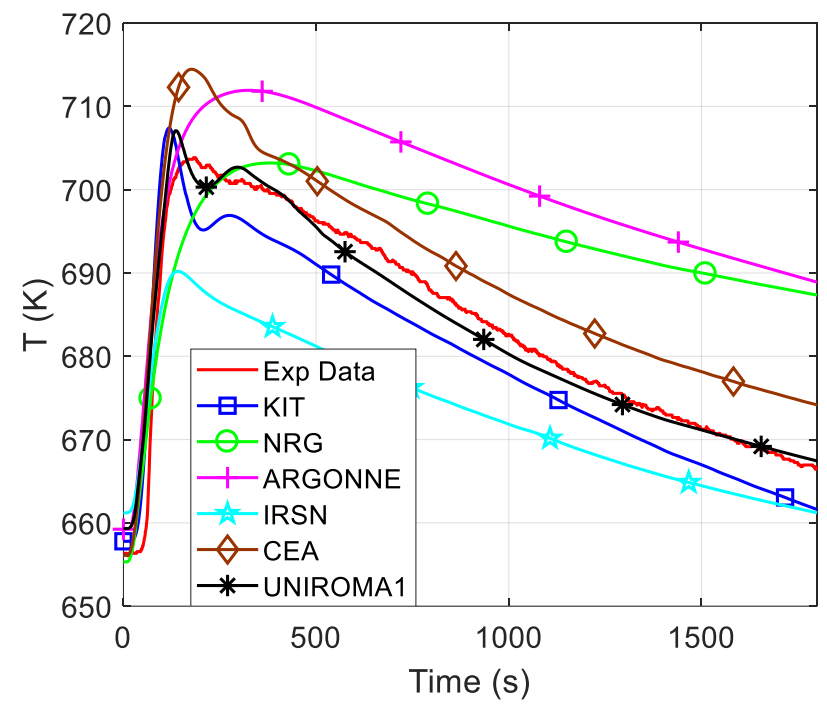

Figure 19 PP2 inlet temperature

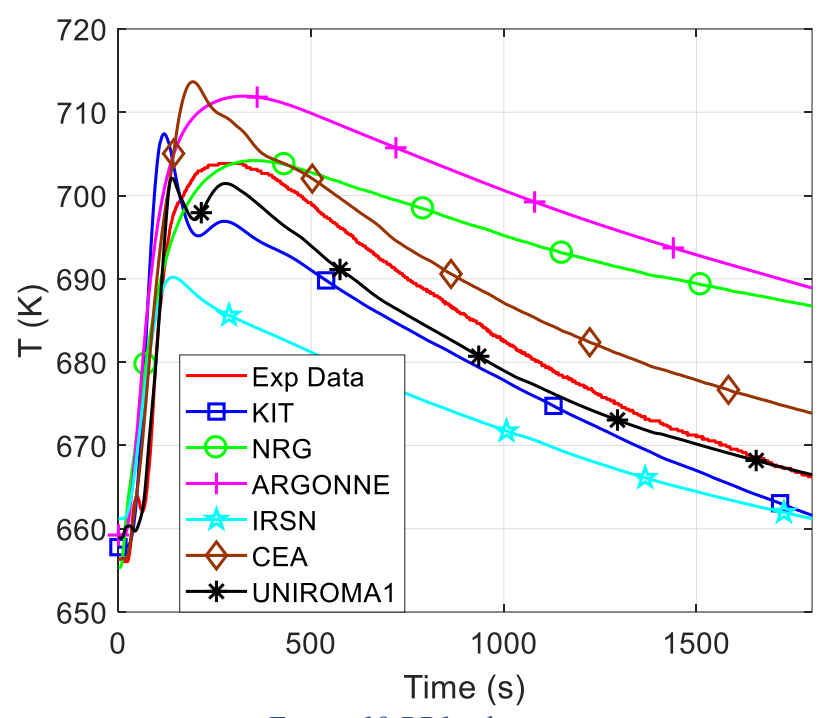

Figure 18 PP1 inlet temperature

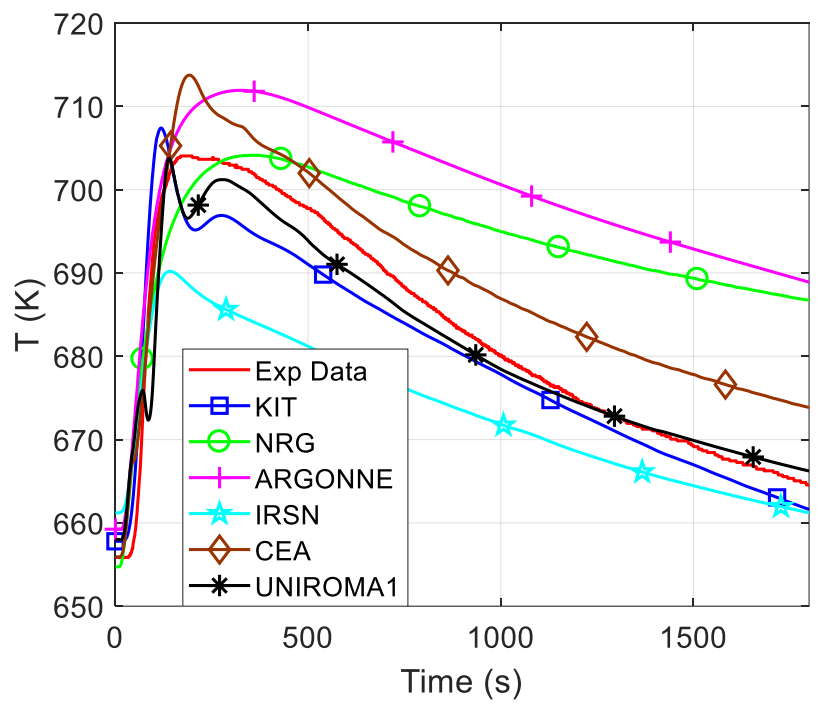

Figure 20 PP3 inlet temperature

The PPs continue to operate and the primary mass flow rate through the core remains quite constant during the test (a little variation occurs due to the temperature variation of the sodium, according to the homologues curves implemented in the pump models).

The PPs inlet temperatures trend lead these PPs mass flow rate variations, reported in Figure 21 and Figure 22. The short-term trend shows a reduction of the mass flow rate due to the PP inlet temperature increase. During the long term this trend is inverted with a gradual increment in the mass flow rate. In the UNIROMA1 simulation results it is possible to view the effect of flow variation caused by the peaks in the PP1 and PP3 inlet temperatures. No direct PPs mass flow rates measurement is available for a direct comparison in this benchmark. 


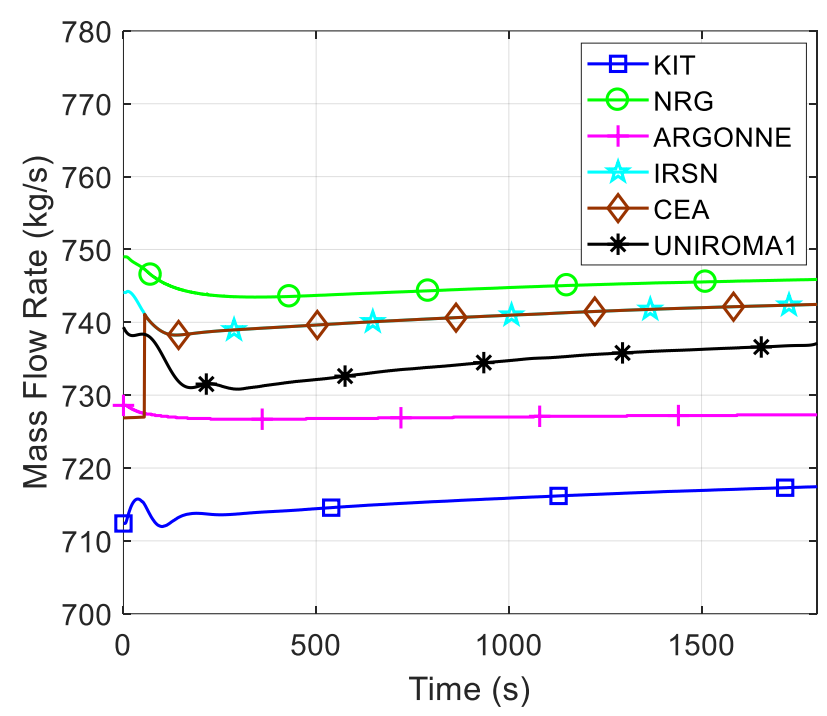

Figure 21 PP1 mass flow rate

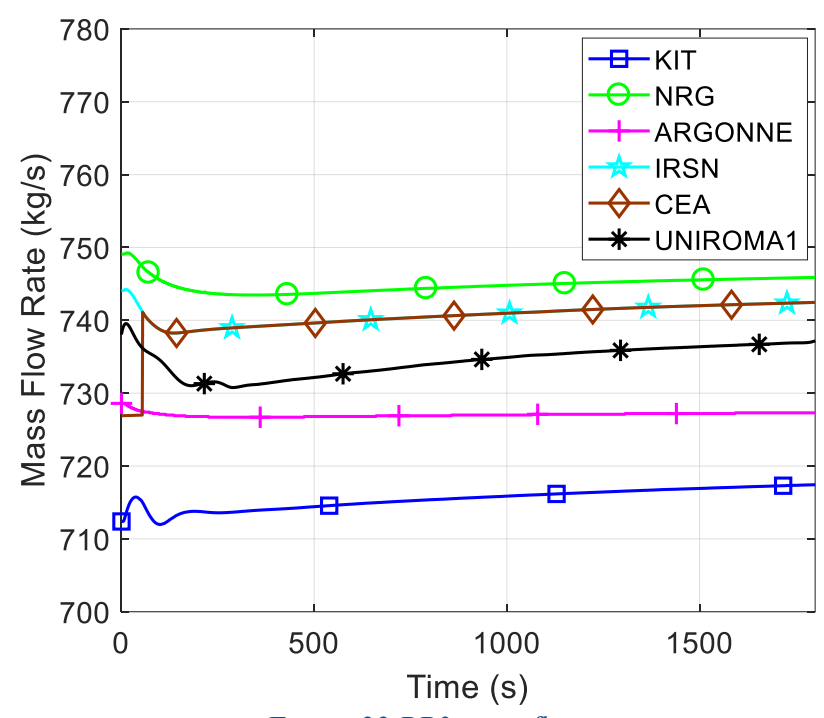

Figure 22 PP3 mass flow rate

The average core outlet temperature is compared in Figure 23. Due to the automatic shutdown, the core power decreases from 5 to 45 seconds. It results in a cold shock at the outlet of the core. The fast decrease is well predicted by the codes, except for ASTEC-Na that overestimates the minimum temperature. After the cold shock, the increase of temperature is reproduced by the codes, following the qualitative trend of the PP inlet temperature, highlighting discrepancies with the experimental data. The cold shock is observed in the hot pool with a delay by the IHX inlets (Figure 24, Figure 25 and Figure 26). The experimental data highlights a thermal inertia effect due to the large volume of sodium contained in the hot pool. In fact, the lower peak of the core outlet temperature is not observed at the IHX inlets. SPECTRA, SAS4A/SASSYS-1 and CATHARE show capability to reproduce this effect that is not observed in the rest of the simulations. The same qualitative trends are maintained at the outlet of the IHX (see Figure 17). The temperatures spread found in long-term is mainly due to the different effects of the hot pool mixing during the cold shock. After the cold shock, the decrescent trend agrees between almost all the simulations but is not coherent with the experimental data. This difference could be explained by an underestimation of the heat losses (through the VCS or the upper part) used as boundary conditions in the models.

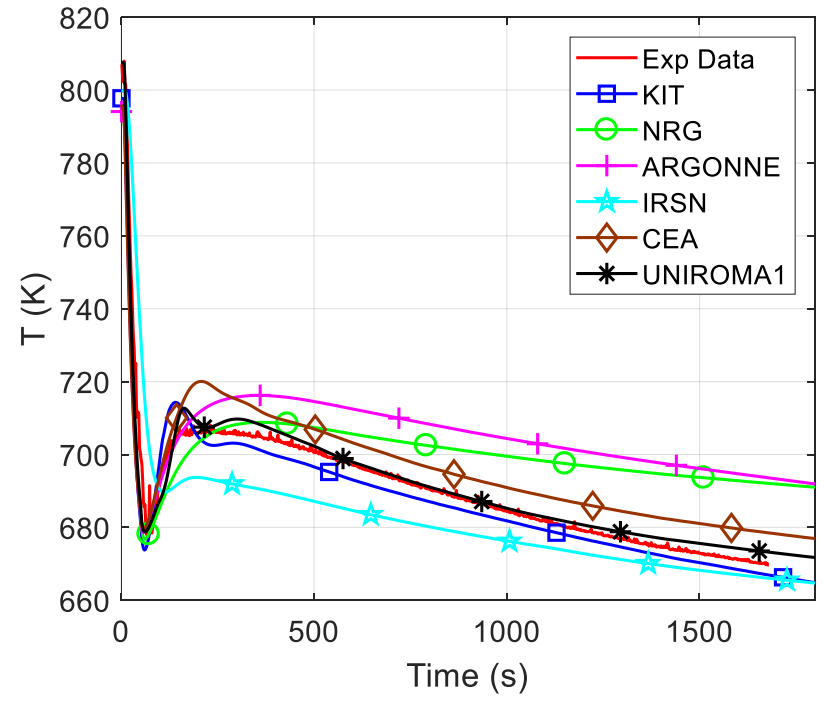

Figure 23 Core outlet temperature

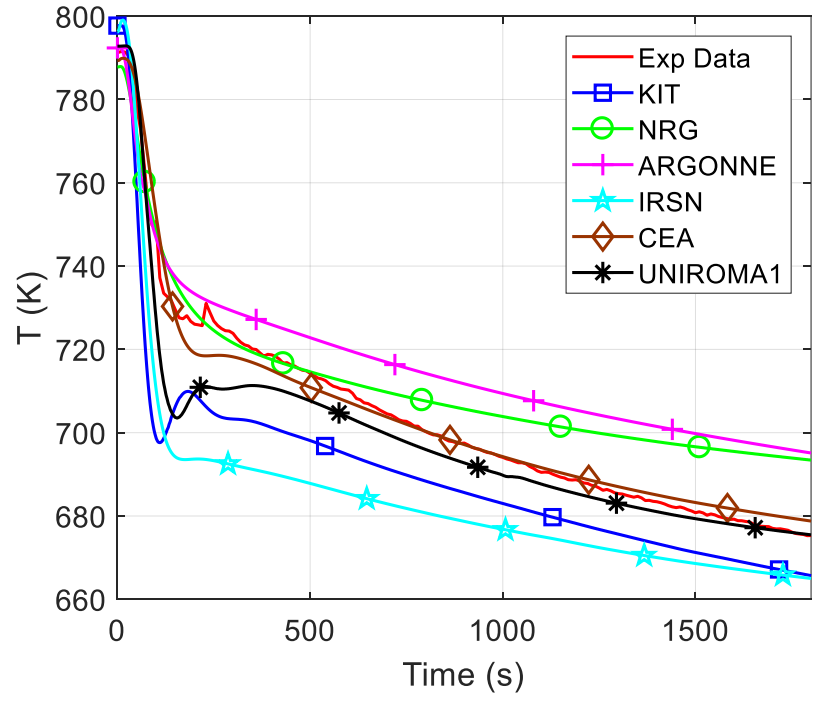

Figure 24 IHX-K inlet temperature 


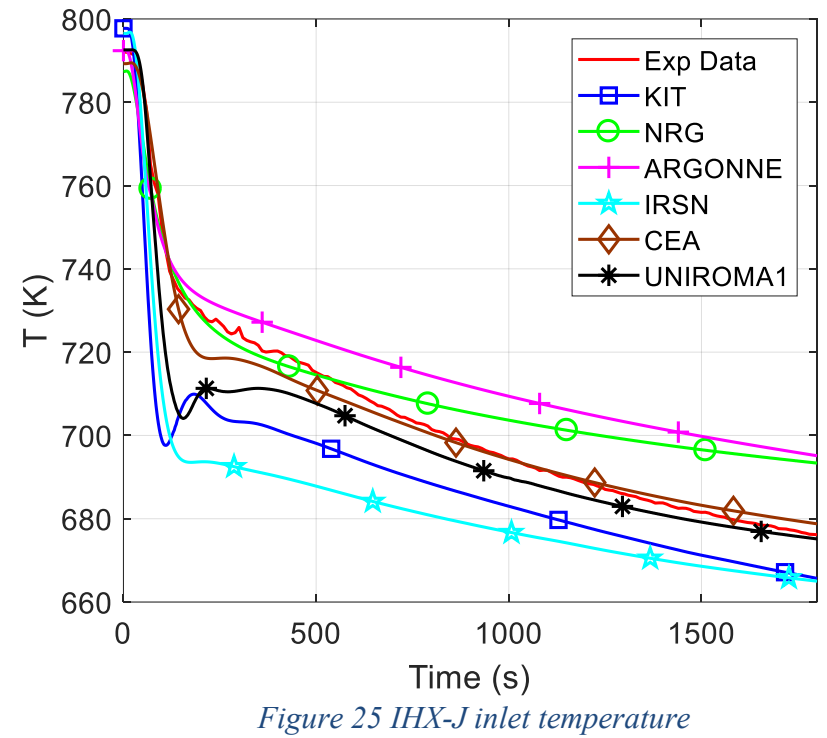

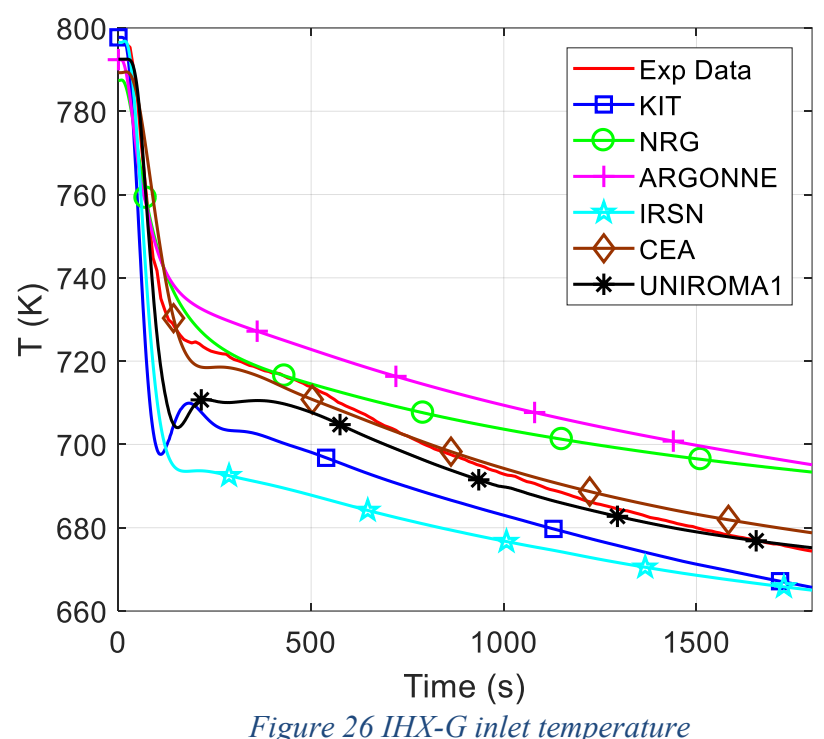

Figure 26 IHX-G inlet temperature

\section{CONCLUSIONS}

The dissymmetric test has been selected as the transient test for the validation benchmark in the framework of the H2020 SESAME project. This test offered useful data for the validation of the thermal-hydraulic system codes, focusing on the capability of the codes to reproduce three-dimensional asymmetry during an accident scenario. Another part of the benchmark is correlated to the STH-CFD coupled calculations and is not here reported.

Six participants were involved in the validation benchmark, performing the calculation with six different thermal-hydraulic system codes: CATHARE, RELAP5-3D, ATHLET, SPECTRA, SAS4A/SASSYS-1 and ASTEC-Na. The nodalization schemes were independently developed, following the reference data provided by CEA.

The full power calculations have highlighted the codes capability to reproduce the normal operation of the reactor. Minor discrepancies between simulations and experiment have been observed, mainly contained within $5 \%$ of error. Starting from the steady state results, the transient calculations have been performed assuming the dissymmetric test boundary conditions provided by CEA. The asymmetric distribution of the flow rate through the secondary loops leads to an asymmetric evolution on the primary system. All the participants have shown a good prediction of the experimental data, even if some discrepancies have been highlighted. Most of the codes are not able to predict the peak temperature at the PP1 inlet during the first minutes of the test. An important feature is the thermal inertia provided by the hot pool, which results in the decrease of the cold shock between the core outlet and the IHXs inlet. CATHARE, SPECTRA and SAS4A/SASSYS-1 have highlighted capabilities to reproduce this effect.

The three-dimensional nodalization of the pool, adopted in RELAP5-3D, seems to simulate better the buoyancy effect inside the large pool as shown at the PP1 inlet where the temperature peak is predicted, with a little underestimation of the maximum value. However, the same effect has been observed at the PP3 inlet, after the delay hot shock at the IHX-J and IHX-G, not highlighted in the experimental data. A similar feature has been observed in the STH-CFD coupled analysis results. The ATHLET standalone simulation can provide a good evolution of local parameters, but the detailed local 3D phenomena cannot be predicted.

In the long-term analysis, a large dispersion of the results has been observed, mainly due to the discrepancies of the temperature reached in the first phase by different models. These discrepancies could be justified by the different energy removed by the IHXs in this period, as showed in Figure 15. After this phase, the mean temperature long-term derivative of all participants is globally different than the experimental value (except for the ATHLET results). This could be explained with an underestimation of the real heat losses in the Phénix reactor.

\section{ACKNOWLEDGMENT}

The SESAME project has received funding from the Euratom research and training programme 2014-2018 under grant agreement No 654935.

\section{NOMENCLATURE}

Symbol

ARGONNE

ASTEC

ATHLET
Quantity

Argonne National Laboratory

Accident Source Term Evaluation Code

Analysis of THermal-hydraulics of LEaks

and Transients 


\begin{tabular}{|c|c|}
\hline CATHARE & $\begin{array}{l}\text { Code for Analysis of THermalhydraulics } \\
\text { during an Accident of Reactor and safety } \\
\text { Evaluation }\end{array}$ \\
\hline CEA & $\begin{array}{l}\text { French Alternative Energies and Atomic } \\
\text { Energy Commission }\end{array}$ \\
\hline CESAR & $\begin{array}{l}\text { Circuit Evolution during a Severe Accident } \\
\text { in a Reactor }\end{array}$ \\
\hline CFD & Computational Fluid Dynamics \\
\hline ENEA & $\begin{array}{l}\text { Italian National Agency for the New } \\
\text { Technologies, Energy and Sustainable } \\
\text { Economic Development }\end{array}$ \\
\hline Gen-IV & Generation IV \\
\hline GRS & $\begin{array}{l}\text { Gesellschaft für Anlagen- und } \\
\text { Reaktorsicherheit }\end{array}$ \\
\hline H2020 & Horizon 2020 \\
\hline HTC & Heat Transfer Coefficient \\
\hline HTR & High Temperature Reactors \\
\hline IHX & Intermediate Heat eXchanger \\
\hline IRSN & $\begin{array}{l}\text { Institut de Radioprotection et de Sûreté } \\
\text { Nucléaire }\end{array}$ \\
\hline KIT & Karlsruhe Institute of Technology \\
\hline L1 & Loop 1 \\
\hline L3 & Loop 3 \\
\hline LMFR & Liquid Metal-cooled Fast Reactors \\
\hline LOOP & Secondary Loop \\
\hline LWR & Light Water-cooled Reactor \\
\hline MFR & Mass Flow Rate \\
\hline MSR & Molten Salt-fueled Reactors \\
\hline MULTID & Multi-dimensional \\
\hline NRG & Nuclear Research and consultancy Group \\
\hline PP & Primary Pump \\
\hline PS & Primary Side \\
\hline RELAP & $\begin{array}{l}\text { Reactor Excursion and Leak Analysis } \\
\text { Program }\end{array}$ \\
\hline SESAME & Thermal-hydraulics Simulations and \\
\hline & $\begin{array}{l}\text { Experiments for the Safety Assessment of } \\
\text { Metal cooled reactor }\end{array}$ \\
\hline SFR & Sodium-cooled Fast Reactor \\
\hline SMR & Small Modular Reactor \\
\hline SPECTRA & $\begin{array}{l}\text { Sophisticated Plant Evaluation Code for } \\
\text { Thermal-Hydraulic Response Assessment }\end{array}$ \\
\hline SS & Secondary Side \\
\hline STH & System Thermal-Hydraulic \\
\hline UNIROMA1 & "Sapienza" University of Rome \\
\hline VCS & Vessel Cooling system \\
\hline
\end{tabular}

\section{REFERENCES}

Alcaro F., Doolaard H., 2018. "PHENIX SPECTRA/CFD simulations. Deliverable D5.6, SESAME project - WP5.

Austregesilo, e. a. H., 2016. ATHLET 3.1A Models and Methods. Gesellschaft für Anlagen- und Reaktorsicherheit (GRS) gGmbH 64(2), p. GRS-P-1 / Vol. 4 Rev. 4.

Chailan L., Bentaïb A., Chatelard P., 2017. Overview of ASTEC code and models for Evaluation of Severe Accidents in Water Cooled Reactors. IAEA Technical Meeting on the Status and Evaluation of Severe Accident Simulation Codes for Water Cooled Reactors, Vienna (Austria), October, 9-12.

Chatelard P., Belon S., Bosland L., Carénini L., Coindreau O., Cousin F., Marchetto C., Nowack H., Piar L., Chailan L., 2016. Main modelling features of ASTEC V2.1 major version. Ann. Of Nucl. En., vol 93, pp. 83-93.

Del Nevo A., Martelli E., 2016. Validation of a Three-Dimensional Model of EBR-II and Assessment of RELAP5-3D Based on SHRT-17 Test. Nuc. Tech., vol. 193, pp. 1-14, https://doi.org/10.13182/NT14-152.

Fanning T.H., Brunett A.J., Sumner T., eds., 2017. The SAS4A/SASSYS-1 Safety Analysis Code System: User's Guide. Argonne National Laboratory, ANL/NE-16/19.

Fink J.K., Leibowitz L., 1995. Thermodynamic and Transport Properties of Sodium Liquid and Vapor. Argonne National Laboratory, ANL/RE-95/2. 
Giannetti F., Narcisi V., Subioli A., Del Nevo A., 2018. Phénix transient analysis for the assessment of RELAP5-3D based on dissymmetric test benchmark. Proc. of the $26^{\text {th }}$ International Conference on Nuclear Engineering, London, England, July $22-26$. DOI:10.1115/ICONE26-82419

Girault N., Van Dorsselaere J.P., Bandini G., Buck M., Champigny J., Hering W., Herranz L.E., Raison P., Reinke N., Tucek K., Verwaerde D., 2013. The European JASMIN project for the development of a new safety simulation code, ASTEC-Na, for Na-cooled Fast Neutron Reactors. International Conference on Advances in nuclear Power Plants, Jeju Island, Korea, April, 14-18.

Grosjean B., Li S., 2015. Data Package for Phénix Dissymmetrical Test Benchmark. Deliverable D4.1, SESAME project - WP4.

Lyon R.N., 1951. Liquid Metal Heat Transfer Coefficients, Chem. Engng. Progr., Vol. 47 (2), pp. 75-79.

Mikityuk K., 2009. Heat transfer to liquid metal: Review of data and correlations for tube bundles, Nuclear Engineering and Design, 239, pp. 680-687.

Mochizuki H. and Takano M., 2009. Heat transfer in heat exchangers of sodium-cooled fast reactor systems. Nucl. Eng. Des., vol 239, pp 295-307.

Narcisi V., Giannetti F., Subioli A., Del Nevo A., Caruso G., 2019a. Assessment of a RELAP5-3D three-dimensional analysis based on PHÉNIX dissymmetric transient test. Jou. Of Nucl. Eng. And Rad. Sci. (in Press)

Narcisi V., Giannetti F., Caruso G., 2019b. Investigation on RELAP5-3DC capability to predict thermal stratification in liquid metal pool-type system and comparison with experimental data. Nucl. Eng. Des., vol. 352, 110152

Nikuradse I., 1936. Laws governing turbulent flows in smooth tubes. Probl. Turbulentnosti, 75, ONTI Press.

Novendstern E.H., 1972. Turbulent flow pressure drop model for fuel rod assemblies utilizing a helical wire-wrap spacer system. Nucl. Eng. Des., vol 22, pp 19-27.

Stempniewicz M.M., 2018. SPECTRA Sophisticated Plant Evaluation Code for Thermal-Hydraulic Response Assessment, Version 3.61, November 2018, Volume 1 - Program Description, Volume 2 - User's Guide, Volume 3 - Subroutine Description, Volume 4 - Verification and Validation", NRG report K6202/MSt-180228, Arnhem, The Netherlands.

The RELAP5-3D ${ }^{\odot}$ Code Development Team, 2015a. RELAP5-3D ${ }^{\odot}$ Code Manual Volume I: Code Structure, System Models and Solution Methods INL/MIS-15-36723 Volume I, Revision 4.3.

The RELAP5-3D ${ }^{\odot}$ Code Development Team, 2015b. RELAP5-3D ${ }^{\odot}$ Code Manual Volume IV: Models and Correlations. INL/MIS-15-36723 Volume IV, Revision 4.3.

Uitslag-Doolaard H.J., Alcaro F.,Roelofs F., Wang X.,Kraus A., Brunett A., Thomas J.,Geffray C., Gerschenfeld A., Multiscale modelling of the Phénix Dissymmetric Test Benchmark, 2019, (in this Special Issue)

Vasile A., Fontaine B., Vanier, M., Gauthe P., Pascal V., Prulhiere G., Jaecki P., Tenchine D., Martin L., Sauvage J.F., Dupraz R., Woaye-Hune A., 2010. The Phénix final tests. In: ENC-2010, Barcelona, Spain, May 30 - June 2.

William T. Sha and Brian E. Launder, 1979. A model for turbulent momentum and heat transport in large rod bundles. ANL-77-73 